\title{
The potential for computational IT tools in disaster relief and shelter design
}

\author{
Noorullah Kuchai", Paul Shepherd, Juliana Calabria-Holley, Alexander Copping, Aude Matard and David Coley
}

\begin{abstract}
The expanding use of IT has brought an increase in productivity to the world of business, industry and commerce. However, this is not mirrored by an equivalent growth in the use of IT by aid agencies in post-disaster situations. We report a pioneering two-stage study which tested the appetite for the increased use of computational IT tools in this sector, assessed their level of usefulness and whether they can be practically implemented. Thirty aid workers across nineteen countries were surveyed on their use of IT and computational tools in shelter design and provision. The key finding was that none of the participants used any building simulation tools or software packages in any of the design stages of shelter construction. Using this result, two example tools were created-one assessing daylighting and the other environmental impact. A second survey involving 48 aid workers was then carried out to record their experience of using the new tools and $97 \%$ of the participants identified a need for such shelter design tools. The majority felt that the new tools were useful and that they would like to use similar tools in their work, most of them preferring tools in the form of web applications. It is concluded that humanitarian workers in the shelter sector are very willing to adopt IT-based computational tools in their work and would appreciate doing so, but only if they have access to suitably simple tools which are quick to use and easy to learn.
\end{abstract}

Keywords: Information technology, Computational tools, Post-disaster relief, Shelter, Humanitarian aid workers, Design simulation

\section{Background}

The number of people fleeing war, persecution and conflict exceeded 70 million in 2018, which is the highest level of displacement for 70 years (UNHCR, 2018; UNOCHA, 2018). It is estimated that future climate change could cause an additional 140 million people to be displaced by 2050 in just three regions of the developing world: Sub-Saharan Africa, South Asia and Latin America (Rigaud et al., 2018). Given the widespread adoption of IT (information technology) and computer modelling by commerce and industry over recent decades, it seems reasonable to investigate whether the level of adoption has been similar in the humanitarian aid response sector and whether further adoption by the aid sector might be useful and practical. Laguerre (2013) examined at least

\footnotetext{
* Correspondence: n.kuchai@bath.ac.uk

Department of Architecture and Civil Engineering, University of Bath, Bath BA2 7AY, UK
}

four aspects of the aid sector to which IT has contributed and where its impact is most visible: cash management (mobile banking), remittance flows, tax disbursed to government funds, and employment growth in both formal and informal sectors. Indeed, aid organisations represent an important source of funding for projects involving IT in low- and middle-income countries. However, limited numbers of such organisations acknowledge IT as a new and important asset in the development sector (Schware and Choudhury, 1988; Belliveau, 2016; Benrós et al., 2011; Carrasco and O'Brien, 2018; Cheng, 2018). The potential contribution of IT was also identified by Grimes and Lyons (1994), including centralisation and decentralisation as possible outcomes of adopting IT. Major restricting factors include political agendas and the availability of funds and the necessary skills (Downs, 1987; Bhattacharya, 2001; Andersen et al, 2002; Benrós., et al. 2011; Biswajit, M. and B. Bhattacherjee, 2015 ). Although low- and middle-

\section{Springer Open}

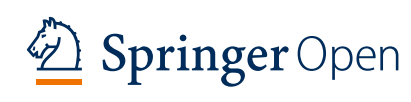

(c) The Author(s). 2020 Open Access This article is licensed under a Creative Commons Attribution 4.0 International License, which permits use, sharing, adaptation, distribution and reproduction in any medium or format, as long as you give appropriate credit to the original author(s) and the source, provide a link to the Creative Commons licence, and indicate if changes were made. The images or other third party material in this article are included in the article's Creative Commons licence, unless indicated otherwise in a credit line to the material. If material is not included in the article's Creative Commons licence and your intended use is not permitted by statutory regulation or exceeds the permitted use, you will need to obtain permission directly from the copyright holder. To view a copy of this licence, visit http://creativecommons.org/licenses/by/4.0/. 
income countries have enthusiastically embraced IT, they are equally aware of the negative impact that dependence on imported technology and services might have (Bortnick, 2010). Figure 1 shows that there are some cases in which technologies that would be seen as advanced outside the aid sector have also been adopted by the humanitarian aid agencies, even in challenging conditions such as insecure and inaccessible remote locations. Jacobsen (2017) traced the development of the United Nations High Commissioner for Refugees (UNHCR) biometric adaptation of pilot projects and the way that the emergence of digitalized biometric refugee data had affected the relationship between the UNHCR, donor states, host states and refugees.

One of the areas in which technological advances might play a significant role in humanitarian agencies is in the provision of shelter. Aid agencies are provided with hundreds of different designs and prototypes for shelter-based innovations and most of these products are based on the idea that a single product can function effectively in all settings (Ramalingam et al., 2009; Dabaieh and Alwall, 2018; Daubman et al., 2019). Such product-based innovations can actually be detrimental in the aid sector because they can lead to inappropriate and impractical interventions. Therefore, a different attitude to innovation might be needed to address failures in shelter provision. There is a need for shelter design tools, as opposed to shelter prototypes which tend to be designed by inexperienced architects or engineers who are not involved in managing disaster responses. A simple-to-use design tool would enable aid workers themselves to assess, compare and decide on a particular shelter design type for a specific location. Some modelling and simulation tools concerning disaster response have been developed for emergencies (Yeung and Harkins, 2011; Davis et al., 2011; Benrós et al., 2011; Wutthikornthanawat et al., 2007), but the majority of those tools focus on urban types of emergency, such as fires in office or school buildings, or earthquake incidents, and are often only suitable for small-scale emergency responses. In the event of a disaster which results in mass displacements, rapid housing and camp management solutions are needed. At present, however, existing methodologies for camp management and shelter design face many challenges. These include a lack of inclusive and longer term government policies, gap between aid agencies and host governments, treating shelter projects as of a temporary nature project (while camps last for decades), rigidity towards permanent look of shelters, lack of funds, gap between aid sector and private sectors (academia and specialist consultancies), etc. (Samuelhall. org, 2012; Manfield, 2000; Sabie et al., 2017). The inclusion of stakeholders in the early stage of design, particularly the affected family, is equally important, and a shift of focus from product to process is needed (Global Shelter Cluster, 2018). Computational tools can play a vital role in this transition.

It has been suggested that the solutions developed and prescribed by the aid agencies need a profound revision. There is a need for these solutions to be supported by computer-aided architectural and engineering techniques, tools and design strategies (Benrós et al., 2011; Davis et al., 2011; Yeung and Harkins, 2011; Jinuntuya and Theppipit, 2007; Ajam, 1998; Dabaieh and Alwall, 2018). For example, shelters can be too cold in winter and too hot in summer (Albadra et al., 2017; Fosas et al., 2018). This indicates the need to improve the designs, and IT has a role to play in this, for example, by allowing

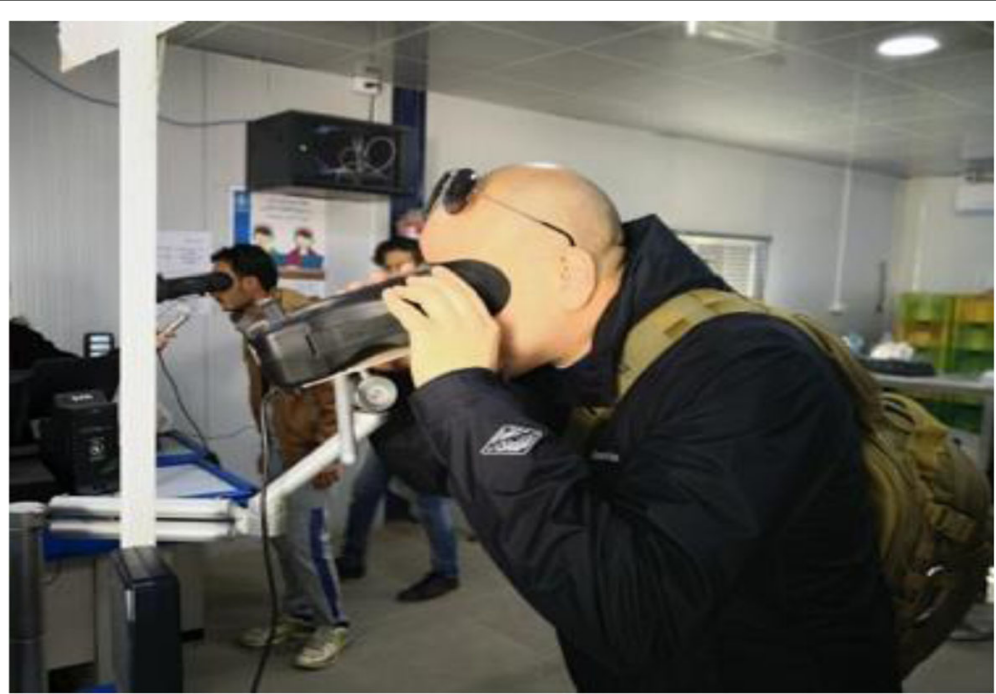

Fig. 1 Retinal recognition system in use in a food distribution centre, Azraq refugee camp, Jordan (photo: Author) 
for thermal modelling prior to the rollout of a design. One key element in developing any technologically supported design solutions and/or tools will be the accurate assessment of the time, information, resources and skills available in the humanitarian sector.

In this paper, we study the use of IT in a post-disaster context, with a focus on shelter design. We also investigate whether there is an appetite for the increased use of IT and how useful IT might be in this sector. The following questions then arise:

1. Do agency staff members use computer tools for design?

2. If yes, on what topics?

3. What other technical approaches do they use?

4. Might they find design tools useful?

5. What level of complexity might they be willing to accept? and

6. How much time might they be willing to invest in using a design tool?

These questions were addressed by means of two separate but sequential surveys. The first survey addressed questions 1 to 3 and the second, questions 4 to 6 . The first was a detailed survey of aid workers in several countries (with the majority of the participants being in the developing world) on their use of IT in shelter provision. Their responses were then used to develop two shelter design tools which were then used as the subject of the second survey of aid workers who had used them.

\section{The adoption of IT by the construction industry and the commercial sector}

It is clear that many aspects of the modern world are connected with the growth of IT (Downs, 1987; Belliveau, 2016). Computation as a design support tool combined with appropriate software has significant potential to make the construction industry more effective and efficient (Bhattacharya, 2001; Molnár et al., 2019). Information technology has been adopted widely in the construction industry and it is difficult to imagine planning, organising, communicating and managing stakeholders on a global scale without using IT within multi-national corporations (Love et al., 2005). IT is helping the construction industry not only to automate its design processes but also during the construction processes itself-robotic construction machinery and 3D printing are key examples. Additionally, the emergence of e-commerce has significantly helped the tendering and bidding processes (Kong et al., 2001). The potential use of IT in completed developments (residential, commercial or communal infrastructures) is also important (Andresen et al., 2002; Elliman and Orange, 2000). There is an intensive demand for IT in the development of smart buildings because of the need for automated and adaptive energy systems, remote monitoring and control systems and several other assistive technologies (Ozumba and Shakantu, 2018). IT has transformed the construction industry from a traditional to an industrial process. Even so, some areas are ripe for further enhancement, such as product definition processes and the use of systems products and recycling, in which IT can play a significant role in improving productivity and quality (Molnár et al., 2019). Construction companies in many developed countries create their own industrialised building concepts that have an underlying reliance on IT (Lessing et al., 2005). Both 2D and 3D CAD (computeraided design) software is used in almost all construction companies (Molnár et al., 2019) and very few of them are unable to handle 3D CAD and BIM (Building Information Modelling) software packages.

\section{Uses of IT in the post-disaster context}

In post-disaster reconstruction, one critical aspect is the communication of information as well as of the required actions to mitigate the risk of any further casualties. This establishes an integral role for IT in the sector (Biswajit and Bhattacherjee, 2015; Farley and Hecht, 1999). Social media, radio, television, mobile phone networks and ICT (information and communication technology) infrastructure can all play crucial roles in all three stages of effective disaster management, the awareness and preparedness, response and risk mitigation, and recovery stages (Kleinau, 2015; Alexander, 2014a; Alexander, 2014b; Barr, 2011). However, a singular technology in a complex process such as disaster management and response would never be sufficient (Ismail et al., 2014; Daubman et al., 2019).

Various types of IT have to be adopted to identify, detect and assess disasters, as well as aid in the accurate identification of the extent of vulnerability of the survivors. Disasters occur suddenly and can have a huge impact, often resulting in the mass displacement of people. Managing the delivery of aid assistance at such a scale poses a great challenge to aid agencies and local governments. To ensure a swift response and sustainable recovery, human error needs to be minimised and rapid collaboration and rapid response is required. Hence, the need and potential for IT in simulation and design optimization arise (Chang et al., 2010).

Currently, the majority of reconstruction and rehabilitation procedures are undertaken manually and limited technology-backed strategies for project implementation are adopted. Automation of the procedures, prediction and simulation of the entire design process for postdisaster activities is needed to help to select rapid, optimal and real-time solutions (El-Anwar et al., 2009). 
Additionally, the communication of critical information between the survivors and rehabilitation stakeholders/ planners is a requirement which needs careful attention to avoid duplication, shortage in the delivery of vital assistance, and corruption, and to enhance quality control and make monitoring more effective (Wang and E.Taylor, 2014). Some of the more traditional information system measures include radios, telephone systems, mobile phones and SMS (short message service), but given the current advanced levels of IT, these measures seem outdated and inadequate. However, at least 100,000 lives were saved by a single phone call in the coastal areas of South East Asia during the 2004 Tsunami (Biswajit and Bhattacherjee, 2015), which highlights the potential significance of even the simplest technology in the aid sector.

Geographical information systems (GIS), which can be defined as a system of both software and hardware, are regularly employed for the storage and retrieval, analysis and mapping of the geographic data of a disaster site. The information provided by GIS is further employed for scientific investigations, as well as for planning and resource management (Erskine and Gregg, 2012). Another application of IT is the extension of GIS to remote sensing technologies and tools for the acquisition and measurement of information about a disaster using a recording device, which gathers the necessary information about a location without physically being there. This is very useful because different agencies tend to work in different areas during a disaster and this technology can keep the agencies virtually connected with the progress of humanitarian aid measures at all sites. It also provides a visual image of critical information during an emergency (De Longueville et al., 2010) and a means of mapping who is doing what and where. The use of spatial data from the web is one of the older, yet effective, uses of IT in many industries, and this includes the aid sector. For several years, spatial data activities were limited to a particular organisation (Goodchild and Glennon, 2010), but the Web 2.0 and mobile application era has made spatial information more accessible. This has played a significant role in reaching wider geographical areas for aid delivery (Langston and Langston, 2008).

The use of IT may be sporadic in post-disaster rehabilitation but it is slowly gaining momentum. One example is the use of social media in disaster risk reduction and crisis management. In the field of postdisaster humanitarian aid, social media (such as blogs) and messaging sites (such as Facebook, Twitter, WhatsApp and Instagram) can be used in several different ways. These include listening to actions and reactions during post-disaster rehabilitation, monitoring the situations from different perspectives, extending and outsourcing the response, as well as collaborative development and furthering the humanitarian causes (Hosein and Nyst, 2013; Alexander, 2014b). Social media are beginning to change the way in which humanitarian interventions are carried out. For example, within the social media context, calls for action and aid come across as requests and heart-warming appeals, rather than direct orders. This approach results in a bigger response and deeper involvement. Furthermore, most organisations now share information over social media, which makes them work as a team rather than as competitors during a crisis (Yates and Paquette, 2011).

\section{Opportunities and obstacles to adopting IT in the aid sector}

The majority of the advanced technologies which are being used in humanitarian aid have fused the physical, digital and biological worlds and the use of technology can question the concepts of war and peace, ethics and human rights (Kleinau, 2015).

A critical review of the literature on humanitarian aid suggests that technology gives humanitarian agencies unparalleled access to war-hit communities (Felter, 2018; Ben Ramalingam, 2016; Jason Susim, 2019; Chaudhri et al., 2019; Arnold et al., 2018; Wilson and Jumbert, 2018; Harvard Humanitarian Initiative, 2011; Gilman, 2014; Lüge, 2014; Comes, 2016; Sandvik et al., 2014). A similar finding was made by the Scientific Foresight Unit and the European Parliamentary Research Service (EPRS) (European Parliamentary Research Service, 2017, 2019). This has ensured the timely and efficient delivery of aid to war-torn areas (Benrós et al., 2011; Daher et al., 2015; Downs, 1987).

Despite the obvious advantages, there are some drawbacks to using technology for humanitarian aid (Bortnick, 2010; Daher et al., 2015; Sandvik et al., 2014) and there are a number of criticisms of their use (O'Driscoll, 2017). For example, using surveillance tools like UAVs (unmanned aerial vehicles) can give rise to ethical and political challenges if the information collected by humanitarian agencies finds its way to one or other faction in a conflict, and might then be used to threaten communities, governments or individuals. This possibility has led to discussions about how the process of gathering humanitarian data could be improved and strengthened (Oldham and Astbury, 2018; Anema et al., 2014). Suggested solutions include a code of conduct for the collection and use of information, training aid workers to use data ethically, and involving the affected communities in how they would like their data to be used and stored (Chang et al., 2011). However, UAVs can help aid workers get a quick overview from above, thanks to their high-resolution, cost-effective insights. Humanitarian drones are today being employed across a 
range of sectors, by organisations as diverse as The World Bank and Geneva International Centre for $\mathrm{Hu}$ manitarian Demining. (Soesilo et al., 2019 \& 2016), and the use of UAV drones in humanitarian action is a rapidly emerging field (Dowson, 2018; Tasevski, 2018). Kalkman (2018) carried out exploratory research into humanitarian aid agencies' use of technologies during post-crisis rehabilitation and found that the use of IT had significantly increased in these areas. It was concluded that technology must not be treated as a neutral fix since it can leave political aftermath if used incorrectly (Raghad and Dave, 2016). It has also been shown that using excessive technology during humanitarian aid activities could result in the domestic and international aid personnel growing distant from the communities they are helping (Carrasco and O'Brien, 2018). The conclusion drawn was that if internet tools are to be used in the development of emergency response systems, then factors such as the accessibility, accuracy, validity, feasibility and scalability of the proposed methods should be carefully assessed, especially when applying them in resource-poor settings (Bartell et al., 2006).

Similarly, despite the positive impact of using social media for humanitarian aid, there is further potential for negative aspects, such as the dissemination of rumours promoting hate and terrorism, facilitating terrorists and undermining the authority of the aid organisations (Kabra et al., 2015). This has prompted an argument about the ethics of using social media during aid activities, but even though there are some clear risks, such as the possible violation of privacy and security, most people view the social media as a good way to uncover corruption and malpractice during aid activities (Alexander, 2014b; Cheng, 2018). Even so, ethical warnings must be heeded to make sure that social media practices are not misused (Hammon and Hippner, 2012).

Others have concerns such as improper or inadequate implementation, as well as potentially high costs of maintenance for complex IT systems. Moreover, it is possible that the proposed technology might not fit (Bond, 2011) with the technology preferred by aid workers, consequently causing more harm than good since the aid actors may be untrained or unprepared to handle such solutions. Moreover, this lack of expertise in the aid sector could lead to a compromise in data and deliverables. It has also been observed that aid workers can have issues with the rapid evolution and development of information technology (Belliveau, 2016). The opportunities are clearly far greater than the obstacles, and the main obstacle in most situations is the lack of information, skills and appropriate tools, which can be mitigated by developing easy-to-use non-specialist tools and providing proper training.

\section{The use of IT-based simulation techniques for shelter design}

Predicting future performance and providing feedback when designing real-world systems or products is the key purpose and primary advantage of simulation activities (Ouyang, 2014). Prior to actual construction or production, simulation allows stakeholders to determine the efficiency of a product or system (Antonelli et al., 2018) and enables designers to investigate problems in a wide range of scenarios (Zhu et al., 2017). This is equally true in building design (Kotireddy et al., 2018; Kneifel and O’Rear, 2017; Nguyen et al., 2014). In some cases, however, generating high-quality simulation models can be very expensive, might take too long or might require a lot of information.

The performance of various types of shelter was analysed by Cornaro et al. (2015) by simulating the thermal properties of different materials and they concluded not only that shelters can be made more comfortable in terms of indoor temperature, but that they can be also made more sustainable in terms of embodied energy, embodied carbon and energy use in general if customised optimization and simulation techniques are used. The building-oriented thermal performance simulation tool 'Energy-Plus' was used by Attia (2014) to analyse the thermal performance of an emergency shelter and various solutions were suggested for improving internal environmental conditions.

Obyn et al. (2014) suggested that using IT-based simulation packages during various stages of shelter design would help the resulting designs to perform better and ensure the thermal comfort and privacy of the occupants. They studied the difficulties in achieving a realistic thermal model of lightweight structures, taking into account the air permeability of fabrics, their light transmission and the overlapping of several elements. A model of the UNHCR standard family tent was created for that study, again using Energy-Plus, enabling an objective assessment of the performance of that shelter in a wide range of contexts. Similarly, the thermal performance of Bedouin tents was assessed and improved using computational simulation by Attia (2014) and that of emergency shelters in extremely cold artificial environments by Ashmore et al. (2003).

There are, however, some barriers to adopting computer-based architectural solutions (Chu et al., 2014). These include the lack of availability of resources and information, cost fluctuations, corruption, socioeconomic complexities and the cultural standards of the affected communities in post-disaster construction contexts. Even though simulation software packages cannot 
address the majority of these barriers themselves, such tools can nevertheless help designers and stakeholders to plan risk-mitigating measures and test those measures at the design stage. The cases briefly described above show that thermal performance is an issue which needs closer examination to determine whether computer simulation can contribute to its improvement.

\section{IT-based simulation for optimising and predicting thermal performance}

Al-Ghamdi (1993) studied thermal comfort in the temporary shelters of pilgrims in Mecca and suggested that the cause of most thermal discomfort was poor ventilation and high relative humidity, which reduced occupants' ability to cool down. Which highlights the need for thermal modelling and simulation before the shelters are manufactured.

Susanti (2015) found that PMV (predicted mean vote) and PPD (predicted percentage dissatisfied) overestimated the comfort level of the tents that were studied. A similar issue was highlighted by Albadra et al. (2017) in a multidisciplinary study undertaken in refugee camps in Jordan, in which it was found that the surface temperature of a white cotton tent can reach $55^{\circ} \mathrm{C}$ and that even the use of a ventilated courtyard had no significant impact during the mid-day period (Al-Hemiddi and Al-Saud, 2001). Knight (1988) investigated the thermal loads associated with a bush fire and predicted that bushfire reflective tent shelters can maintain an internal temperature $40^{\circ} \mathrm{C}$ lower than the outdoor temperature for several minutes, which can play a significant role in saving lives in the case of a fire. In real life, however, 'several minutes' is not long enough. An interesting finding was that the survival of a single occupant in a reflective tent is limited by rises in mean body temperature, whilst multiple occupants can survive slightly higher intensities, with the limiting factor being an excessive rise in air temperature (Taylor et al., 2015). The reflective quality of the fabric could, therefore, be useful for producing safe refugee shelters in hot climates.

Given that most displaced families in refugee shelters and informal settlements cook inside their shelters, they face serious risks of fire, and this makes research efforts to address the issue highly relevant. A study of Palestinian refugee shelters showed that the significant thermal discomforts experienced by occupants in summer and in winter were mirrored in the PMV calculations (Saleh, 2011); it has been found that PMV overestimates in warm conditions and underestimates in relatively cool conditions (Fosas et al., 2018; Saleh, 2011; Humphreys and A, 1976; De Dear and Brager, 1998). A series of architectural strategies have been applied to shelter design using computer simulation techniques, resulting in significant reductions in overheating (Fosas et al., 2018). The comfort band found using logistic regression ranged from $28.4{ }^{\circ} \mathrm{C}$ to $17.2^{\circ} \mathrm{C}$, suggesting significant adaptability of refugees, but still well outside the temperature range found on site. In such settings, natural crossventilation alone will not be sufficient for achieving summer comfort. A shelter solution that successfully includes insulation, and possibly thermal mass, seems more important (Albadra et al., 2017). The thermal conditions inside a temporary shelter were assessed by Crawford et al. (2005) using ESP-r simulation software. They investigated casual gains from both occupants and solar radiation and concluded that the use of such sophisticated techniques and the required materials would only be possible in limited numbers of locations. The validity of these results was, however, limited by the lack of measures to assess accurately the air infiltration values.

As this review of the literature has shown, the use of IT-based engineering/architectural simulation packages by researchers has been evidenced to some extent. However, there is no documented case of aid workers using IT simulation tools. Additionally, the literature review suggests that in at least one field, namely the thermal performance of shelters, simulation has an important role to play.

\section{Methodology}

Because of the geographical spread of aid workers, two sequential online surveys were conducted with those involved in the provision of shelters for displaced people. The aim of the first survey was to evaluate the current shelter design practices by investigating the level of knowledge of the participants in relation to the science of building physics and the perception of aid workers towards having a tailored shelter design tool. The second survey was conducted to assess the usability of shelter design tools in the aid sector. Survey questionnaires were sent to four hundred aid workers (shelter officers) who were either directly or indirectly involved in the provision of shelters, using social media platforms, email addresses and humanitarian websites. Thirty participants responded to the first survey and forty-eight responses were received for the second survey. Google Forms were used as the data collection instrument. Online surveying was adopted because the participants were in various countries. The first survey contained 50 questions, the second eight.

\section{Investigating current design practices and knowledge (survey 1)}

The initial survey was designed using a thematic approach (Tuckett, 2005; Guest et al., 2012; Guest et al., 2011; Braun and Clarke, 2014; Clarke and Braun, 2013) to capture different aspects of shelter design practices and also to understand the level of knowledge of aid workers in relation to different aspects of the science of 
Table 1 Questions asked in the post-user evaluation survey (survey 2)

\begin{tabular}{|c|c|c|}
\hline Chart & Question & Response options \\
\hline A & How easy was the tool to use? & (Rate your answer 1 to $5 ; 1=$ very easy, $5=$ very difficult) \\
\hline B & Was the number of inputs about right? & $\begin{array}{l}\text { ( } 1 \text { to } 5 ; 1=\text { I would have been happy to input more } \\
\text { data; } 5=\text { the tool asked for too much data) }\end{array}$ \\
\hline C & How clear and understandable was the input section of the tool? & ( 1 to $5 ; 1=$ very clear, $5=$ not clear at all) \\
\hline D & How clear and understandable was the output section of the tool? & ( 1 to $5 ; 1=$ very clear, $5=$ not clear at all) \\
\hline E & $\begin{array}{l}\text { Can you imagine using such a design tool on any topic to evaluate existing shelter } \\
\text { designs? }\end{array}$ & $\begin{array}{l}\text { ( } 1=\text { such simple tools might be very useful, } 5=\text { such } \\
\text { simple tools are unlike to ever be useful) }\end{array}$ \\
\hline $\mathrm{F}$ & $\begin{array}{l}\text { Can you imagine using such a tool on any topic to evaluate potential new shelter } \\
\text { designs (remember, this is a general question about computer-based tools, not a } \\
\text { question about a tool for daylight calculations or environmental impact assessment? }\end{array}$ & $\begin{array}{l}\text { ( } 1=\text { such simple tools might be very useful, } 5=\text { such } \\
\text { simple tools are unlike to ever be useful) }\end{array}$ \\
\hline G & $\begin{array}{l}\text { Might you ever recommend such a shelter design tool (on any topic) to your } \\
\text { colleagues who work in the field? }\end{array}$ & ( $1=$ yes, frequently; $5=$ never on any topic) \\
\hline $\mathrm{H}$ & In what form would have you preferred the shelter design tool to be? & $\begin{array}{l}\text { a. Excel-based } \\
\text { b. Web application } \\
\text { c. Standalone interface (internet not needed) }\end{array}$ \\
\hline
\end{tabular}

building physics and other design-related issues. The survey addressed the following topics:

- Lighting technologies in general (daylight and artificial lighting)

- Ventilation strategies
- Thermal comfort in shelters

- Shading technologies

- Energy use and environmental impacts

- The green agenda in shelter projects

- The knowledge and familiarity of aid workers in relation to technical terms of the science of building physics

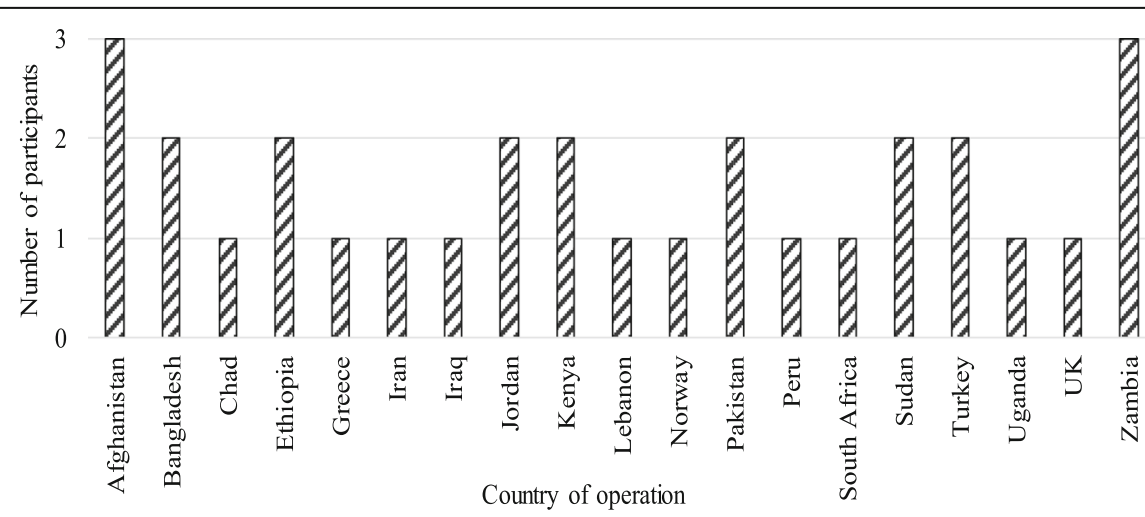

A)

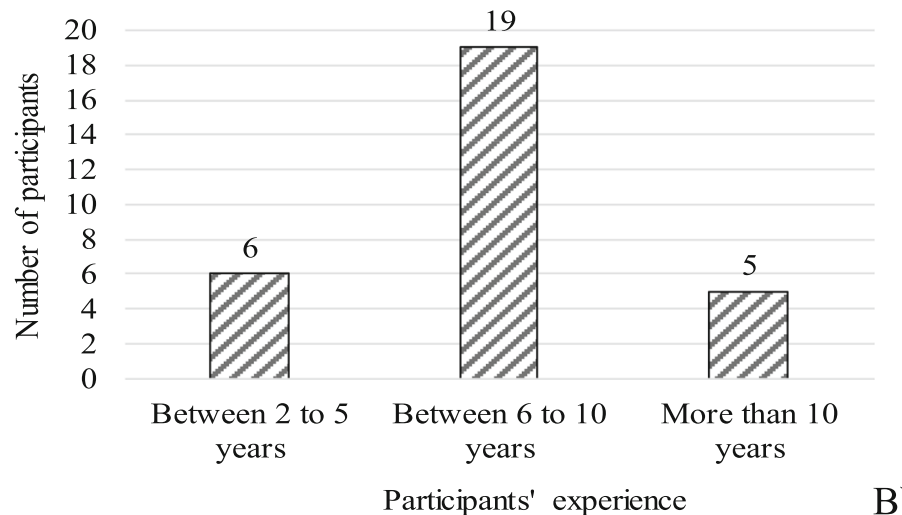

Fig. $\mathbf{2}$ a Location and $\mathbf{b}$ experience of the survey participants 
- The cultural aspects of shelter design and

- The perception of aid workers towards the need for a shelter design tool.

The thirty respondents who returned completed questionnaires included staff from UNHCR, IOM (International Office for Migration), NRC (Norwegian Refugee Council), IRC (International Rescue Committee), OXFAM, Shelter Centre, CARE international and independent aid workers.

Appendix A presents the 50 survey questions and subquestions.

Using the findings from this first survey, two design tools were created, one in the form of a web application to assess the environmental impact of a shelter design and the other in the form of a spreadsheet. With the first tool, participants in the second survey were able to assess the environmental impact of their existing (or any type of proposed new) shelter designs, and with the second tool, they were able to propose a new window layout design for a shelter.

\section{Post-use evaluation (survey 2)}

The two tools described above were sent to aid workers for them to use, test and review in the second survey (see Appendix B). A snapshot of the tools and a list of the required inputs for both tools are given in Appendix C. Links to the second survey were embedded in both tools so that the aid workers could record their feedback easily.

The eight questions in the second survey addressed topics such as usability, ease of understanding, the number of inputs and outputs and the perception of aid workers towards such non-specialist shelter design tools. The survey took a quantitative approach by providing the participants with a Likert-style numeric scale. The

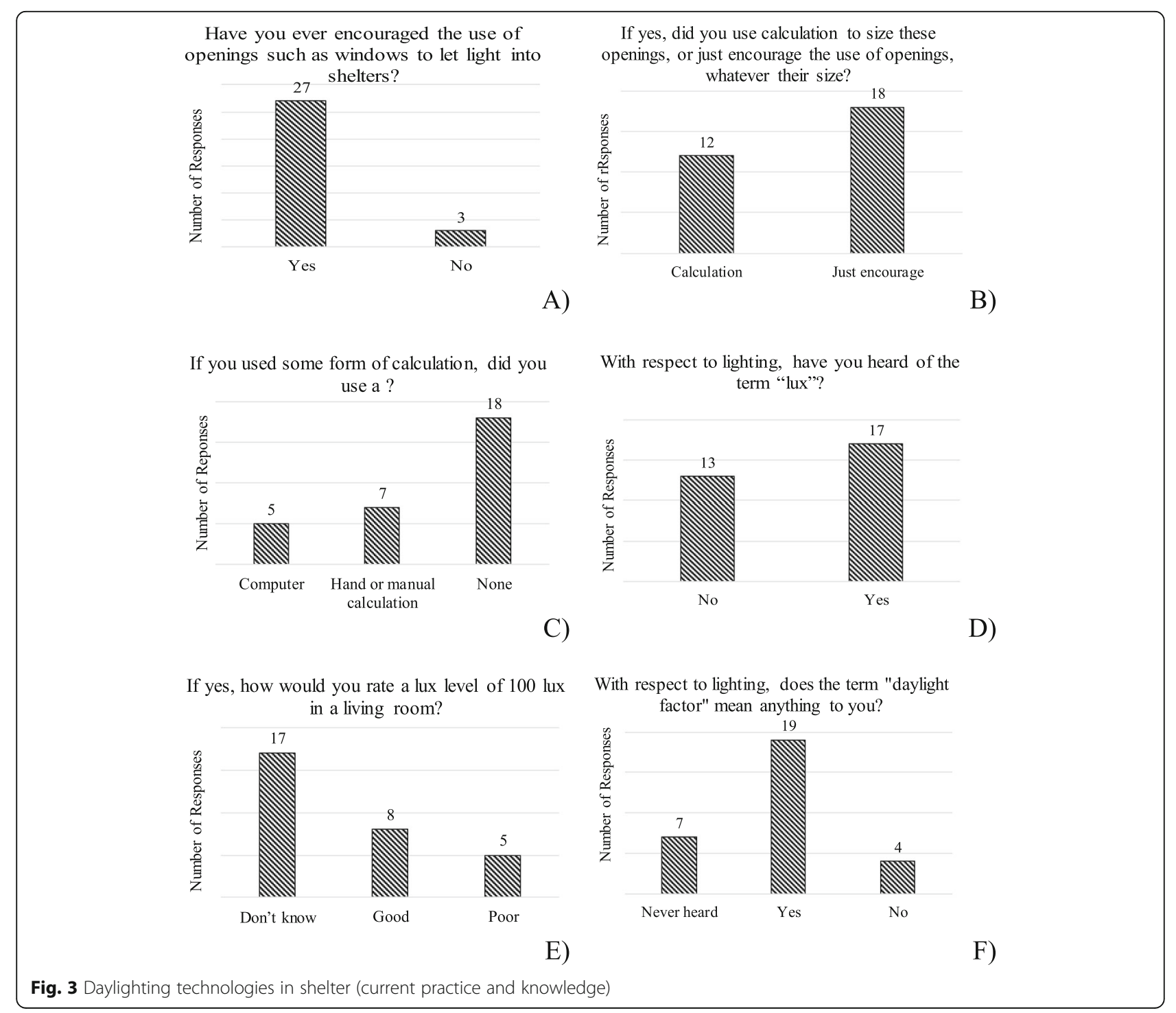


questions are set out in Appendix B and are summarised in Table 1.

Again, the recruitment of respondents was by the Google Forms online surveying tool. Forty-eight participants completed the survey, including staff from UNHCR, IOM, NRC, IRC, OXFAM, Shelter Centre, CARE international and independent aid workers.

\section{Results}

\section{Evaluating current design practices and knowledge} (survey 1)

It is clear from Fig. 2a that wide geographical coverage was achieved across the 30 respondents and a broad level of experience was accessed (see Fig. 2b).

From the results of this survey, it was clear that the vast majority of the participants $(27 ; 90 \%)$ encouraged the use of openings to let light inside the shelters (see Fig. 3a). However, eighteen (60\%) of them had performed no science-based calculations on this; they used the 'just encourage' policy (see Fig. 3b) and twelve (40\%) of them reported performing some sort of calculation whilst only five of the twelve had used a computer, but the use of no particular daylight simulation software was mentioned (see Fig. 3c). The remaining seven (23\%) participants had used a manual calculation method. This was probably due to limited knowledge and lack of information and knowledge amongst the aid workers regarding the subject (see Fig. 3d, e and f) or the unavailability of appropriate and practical resources/tools in the aid sector. Figure $3 \mathrm{~d}$ shows that thirteen participants $(43 \%)$ were not familiar with the technical terminology (such as the unit for the amount of light striking a surface being a lux). They were asked how good or bad a 100-lux level would be for lighting in a bedroom. Five of the seventeen participants who claimed familiarity with the term lux thought that 100 lux is poor whereas eight believed that 100 lux is good (which is not true in most cases). More interestingly, seventeen participants did not know whether 100 lux would be too much light or insufficient. This indicates that the majority of the participants in the survey had limited knowledge of

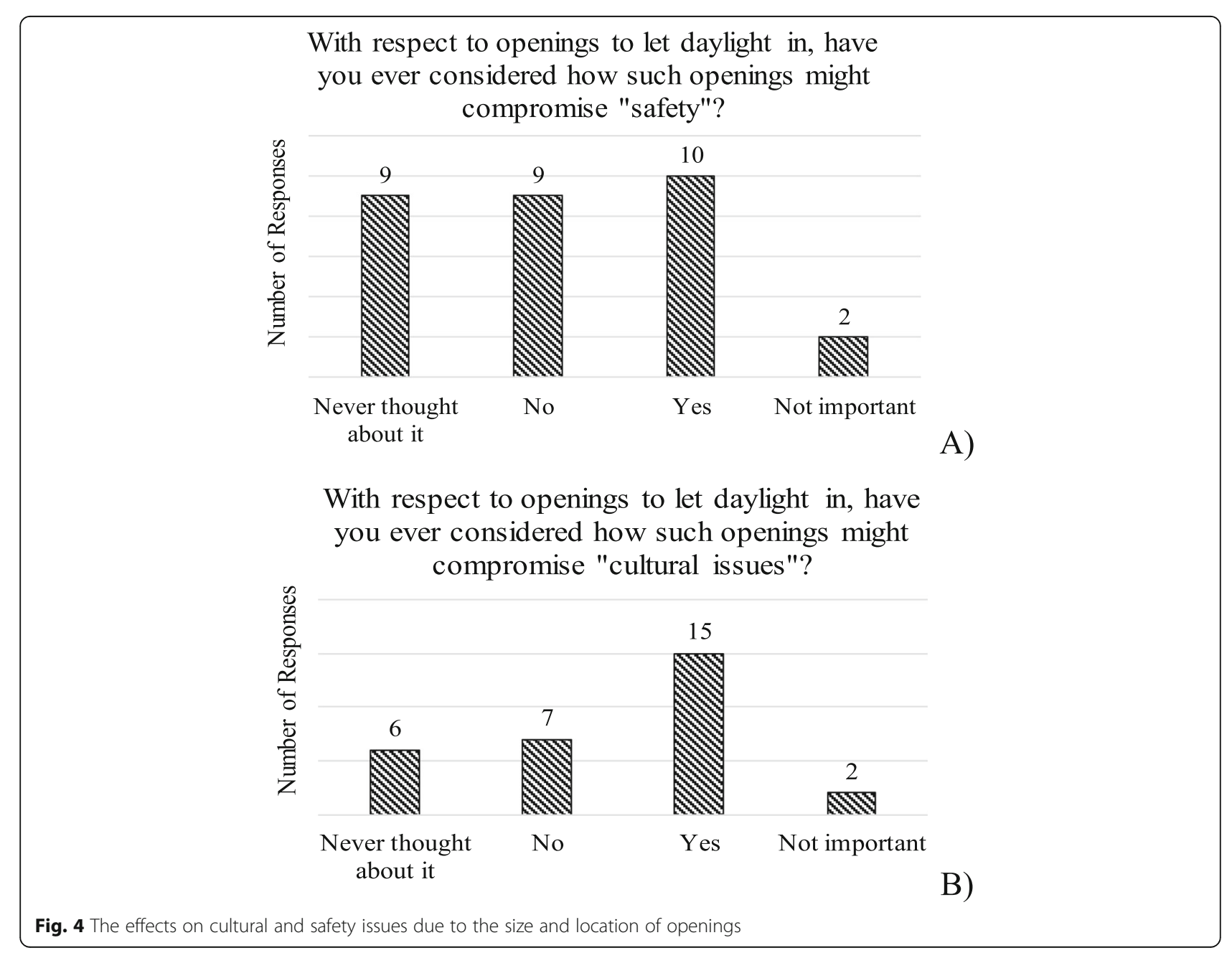


technical terms in relation to lighting technologies. Daylight factor (DF) measures the overall daylight within a space, and Fig 3f shows the responses related to DF, showing it to be a slightly more familiar concept than lux. Some of the participants did use computation to perform DF calculations, but none of them mentioned any specific simulation software or computation tool.

Details of the responses on the effects of size and location of openings (such as windows) on safety and cultural aspects are presented in Fig. 4. It can be seen that only ten $(33 \%)$ of the participants considered that the size and location of openings could compromise the safety of the occupants of shelters (see Fig. 4a). Similarly, Fig. 4b shows that half of them (fifteen participants) considered that the size and location of openings could compromise the cultural issues of the occupants of shelters (such as privacy). The majority of the respondents had never thought about the fact that the location and size of openings might compromise the privacy or safety of the occupants. Lack of consideration about issues such as this will lead to shelters not being used by displaced families or to families having to adapt poorly designed shelters according to their type of clothing. Some of the participants did consider aspects of safety when designing openings but did not consider that this design factor has the potential to compromise the cultural values of refugee shelters.

In terms of artificial lighting, the majority (90\%) of the participants encouraged shelter occupants to use electric lighting equipment; this could include encouraging the use of solar panels or lights (see Fig. 5a). However, nineteen (63\%) of the participants used the 'just encourage' policy (see Fig. 5b). Twenty-six (87\%) of the participants did not perform any sort of calculation regarding artificial lighting technologies, and the remaining $13 \%$ of the participants (see Fig. 5b) used manual calculations (where applicable). Only two participants reported using computers to perform calculations related to artificial lighting in shelters, but they did not report the use of any particular simulation tool.

Figure 6 shows the responses on ventilation and it can be seen that participants are divided into three categories (see Fig. 6a). The majority (80\%) did consider the amount of ventilation required in shelters, and the remaining six $(20 \%)$ were divided into three who thought that it is not important to consider the amount of ventilation required in shelters and three who had not considered the issue at all. Eighteen of the thirty $(60 \%)$ respondents adopted 'just sensible/feasible' approaches when asked about the method used to establish the amount of ventilation required in shelters. Only six (20\%) did perform some sort of calculation to establish the ventilation strategy of shelters (see Fig. 6c) and of these, only one used a computer (see Fig. 6b). However,
Have you ever encouraged the use of "electric lighting" for shelters or homes?

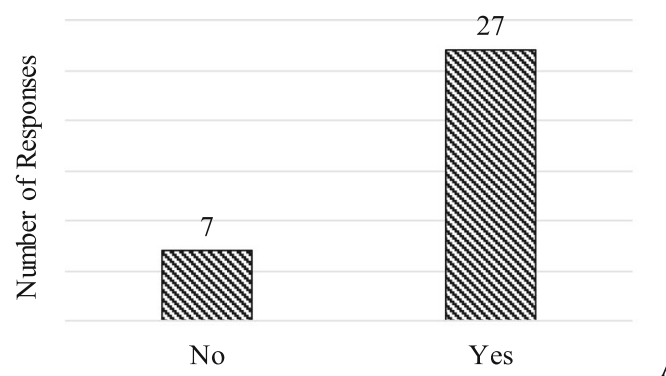

If yes, did you use calculation to size the number or type of lamps, or just encourage the use of lamps, whatever their size?

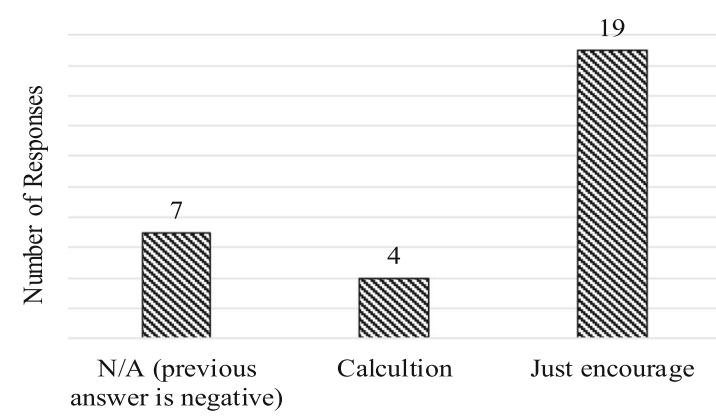

B)

If you used some form of calculation, did you use a?

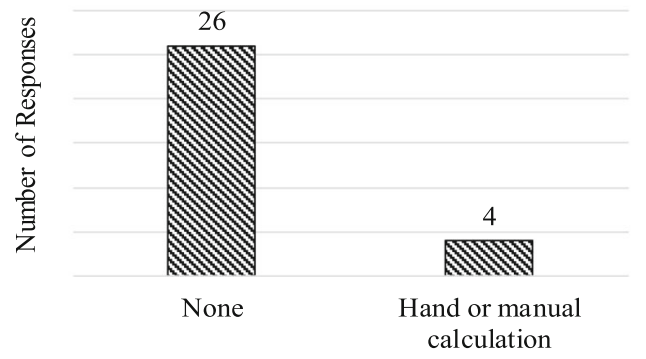

Fig. 5 Artificial lighting in the design of shelters

twenty-four $(80 \%)$ of the respondents did not perform any calculation to establish any ventilation strategies. This is quite concerning because ventilation is an important aspect of refugee shelters, given that most refugee camps and settlements are in hot locations, so it is the key cooling mechanism; it is also relevant to air quality especially when cooking with wood. It was also observed that even though some of the respondents were familiar with technical terms related to ventilation strategies, they did not consider using such techniques in the design process of shelters (see Fig. 6d).

The majority of the survey participants did consider winter and summer temperatures inside shelters (see Fig. 7a) and the majority used a just sensible/feasible 


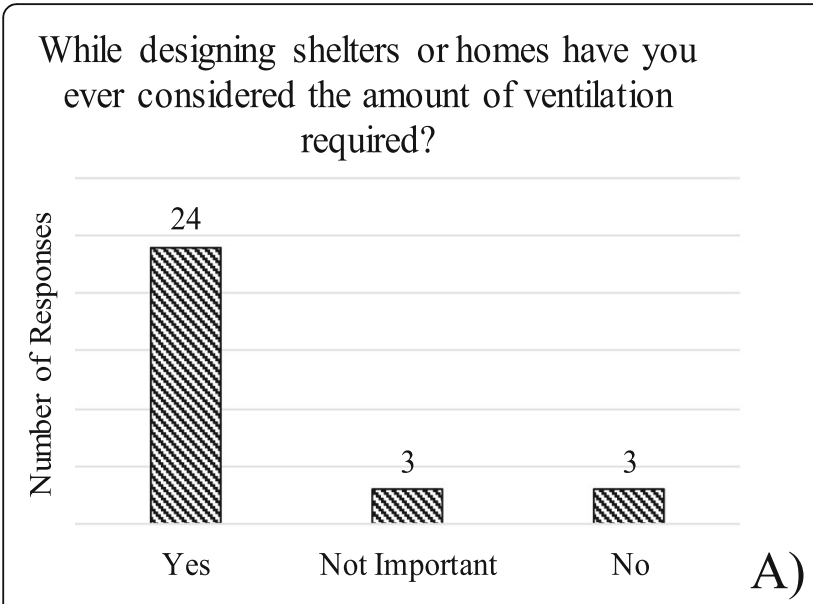

If you used some form of calculation, did you use a?

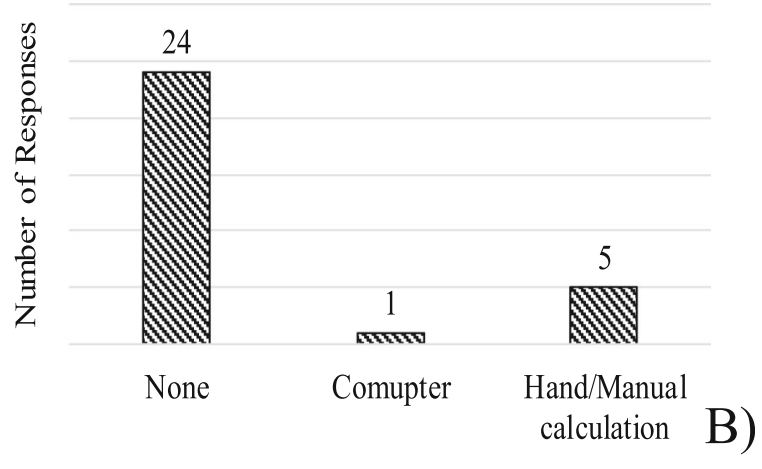

Did you use calculation to design the size or number of openings, or just follow what you believed to be a sensible/feasible policy?

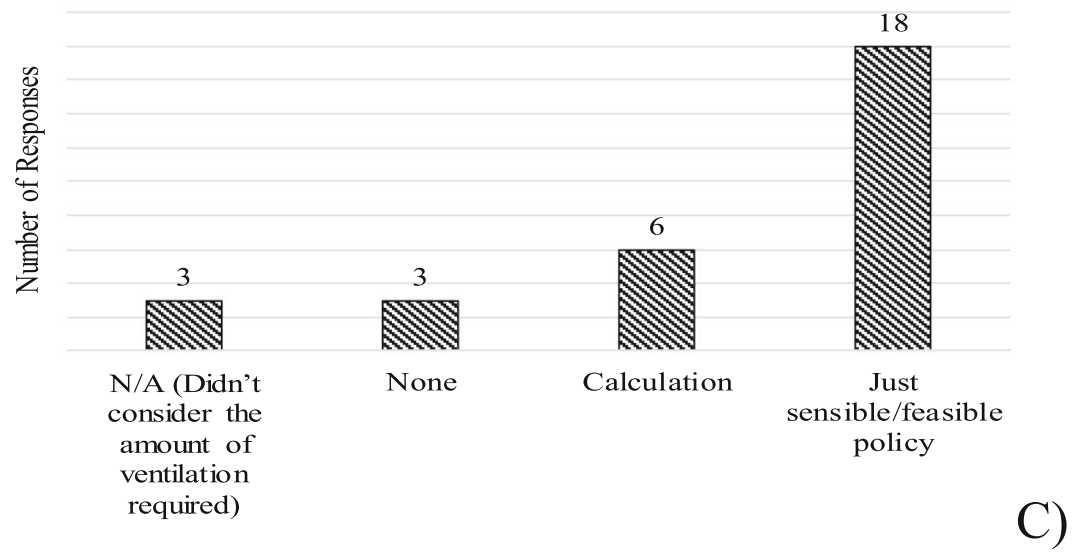

Do these tems mean anything to you? if yes, did you consider consider these strategies in the desgin of shelters ?

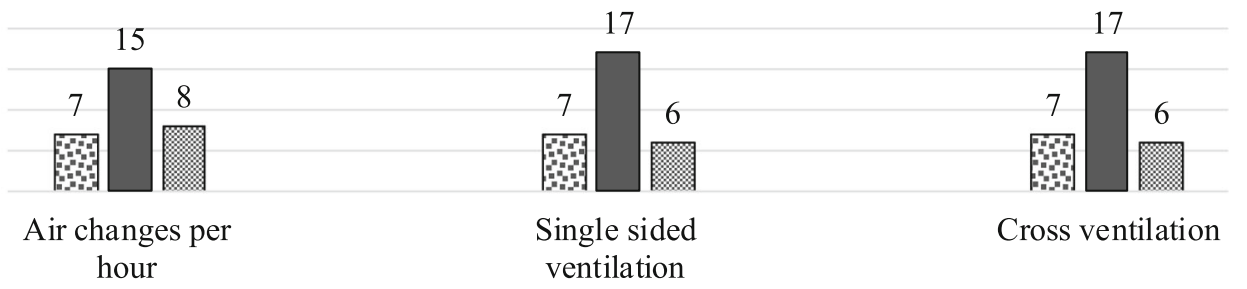

궁 Yes (but I didn't consider it during the design/implementation process of shelters)

$\square$ Yes

圆o

D)

Fig. 6 Ventilation strategies

policy' approach to decide indoor temperatures (see Fig. 7b). Six (20\%) of the participants performed calculations to design indoor temperatures in shelters (see Fig. 7c) and more than half (60\%) did not perform any calculations related to thermal comfort.
Only one used software to calculate and predict the thermal performance of shelters, but no particular simulation software was mentioned by any of them, which indicates that very few or almost none of the participants performed energy simulations in their 


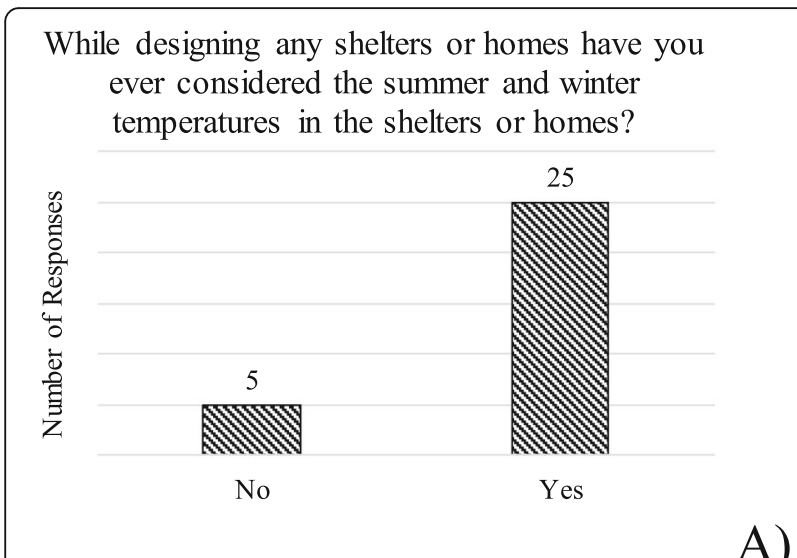

If you used some form of calculation, did you use a?

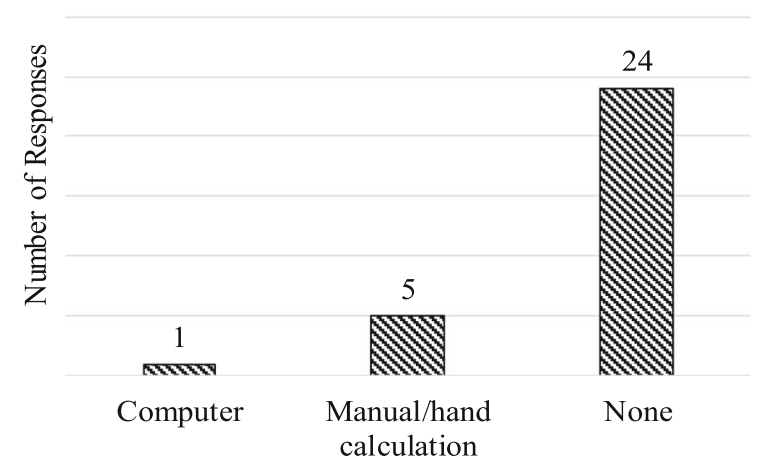

C)
Did you use calculation to improve these

temperatures, or just follow what you believed to be a sensible/feasible policy?

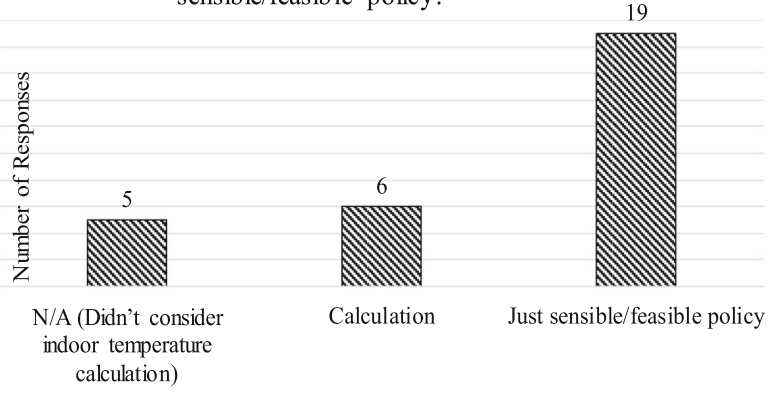

B)

Do the terms "U-value", "R-value" \& "thermall mass" mean anything to you?

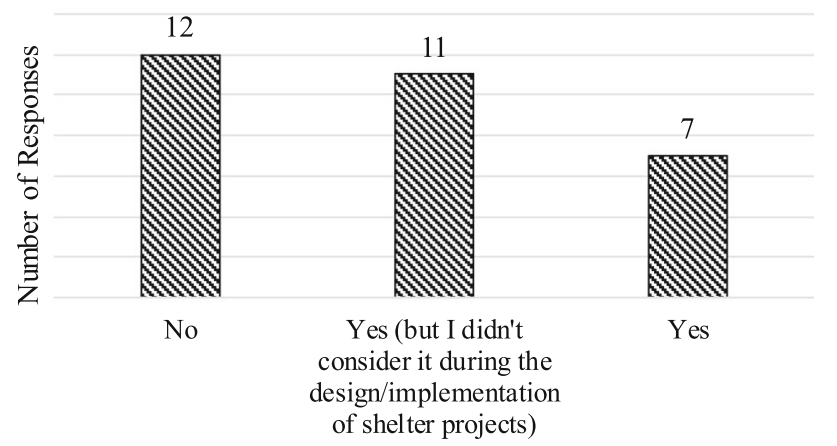

D)

Fig. 7 Thermal comfort

everyday practice. In relation to familiarity with the science of building physics (which plays a main role in predicting thermal comfort in any building), twelve (40\%) of the participants did not know any technical terminology in the subject and eleven (37\%) were familiar with the technical terms but did not apply such techniques in their everyday practices (see Fig. 7d).

Details of practices in relation to designing the size of cooling/heating systems and energy use in shelters are presented in Fig. 8. Very few (eight; 27\%) of the respondents considered the need to design the size of the heating or cooling systems for shelters and the remaining twenty-two (73\%) either did not consider the subject or regarded it as unnecessary (see Fig. 8a). Four of the eight who did consider sizing heating and cooling systems in shelters performed calculations (see Fig. 8b) but all of them used a manual calculation method and reported no use of any computational tools (see Fig. 8c). Half of the participants considered the energy need in shelters but one believed that calculating energy use in shelter projects is not important (see Fig. 8d). Thirteen of the fifteen participants who considered the amount of energy needed in shelters used the 'sensible/feasible' approach. Only three participants reported performing some sort of calculation (see Fig. 8e); two of them used a manual method and only one used a computer, but no particular energy simulation software or computation tools were mentioned (see Fig. 8f).

Figure 9 details the responses on shading technologies and strategies practised by the aid workers, showing that the majority used a 'sensible/feasible' approach to establish the size or design of shading in shelters. Twenty-three (77\%) did consider incorporating shading in the design of shelters (see Fig. 9a) but twenty (67\%) participants used the 'just sensible/feasible policy' approach (see Fig. 9b). Only three (10\%) participants carried out calculations and the rest did not consider calculating how to provide effective shading to reduce the amount of heat from the sun entering a shelter, and of those three, only one used a computation tool to perform the necessary calculations (see Fig. 9c).

There have been various studies of the environmental impact of shelters (Escamilla and Habert, 2015a; Escamilla 

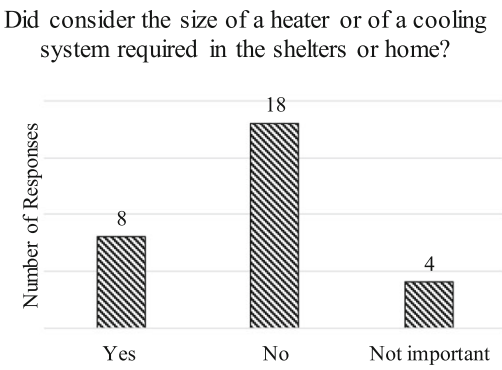

If you used some form of calculation, did you use a?

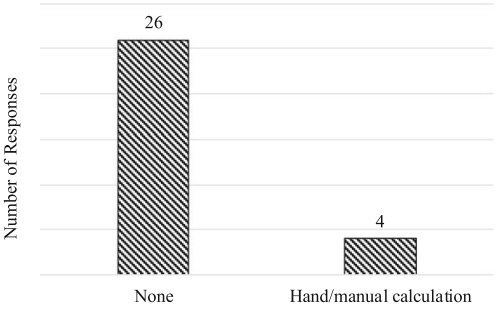

Did you use calculation/calculations to reduce the amount of energy used? or just used

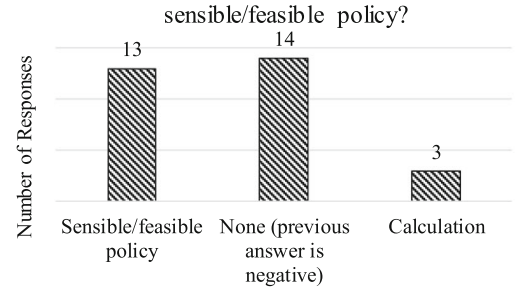

Did you or anyone else use calculation technics to size the heater or cooling system, or just a sensible/ feasible

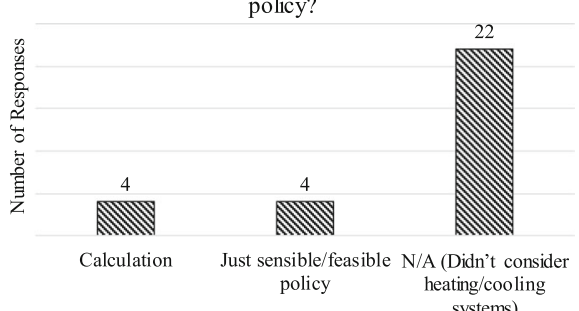

A)

Have you ever considered the amount of energy needed

B) to heat or cool shelters or homes?

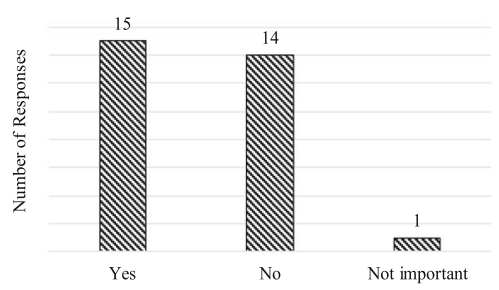

C)

If you used some form of calculation, did you

D) use a?

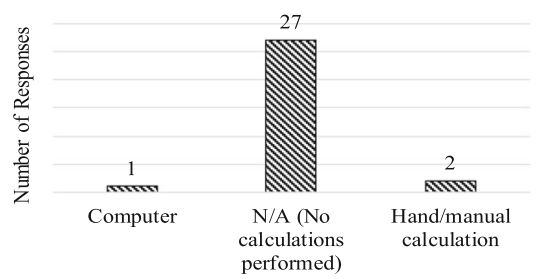

E)

Fig. 8 Energy consumption and design

and Habert, 2015b; Song et al., 2016; Atmaca and Atmaca, 2016; Dong et al., 2018; Félix et al., 2013) and the UNHCR shelter guidelines state the need for shelters to be environmentally friendly (Ashbridge et al., 2012). Although some of the respondents said that they did consider reducing the environmental impact when designing a shelter, the majority used 'just sensible/feasible' policies and no ITbased tools were utilised (see Fig. 10).

Finally, the participants were asked about the potential usefulness of electronic shelter design tools. All but one of the participants (97\%) felt that this was a good idea. However, the participants rated the usefulness of such a design tool differently (see Fig. 11).

In summary, building physics concepts such as daylighting were familiar to the participants but the technical terminologies used in these fields were not well known to them and the use of simulation tools was extremely rare. All but one of the participants confirmed the need for a shelter design tool, but their lack of knowledge about the terminology will clearly make this a challenge.

\section{Post-use evaluation (survey 2)}

As previously explained, the findings of the first survey were used to construct a shelter daylight calculation tool in the form of a Microsoft Excel spreadsheet and an environmental impact assessment tool for shelters in the form of a web application, and these tools were sent to aid workers for them to use, test and review. This enabled these participants to complete the second survey. The results of this survey are shown in Fig. 12.

Of the 48 respondents, the majority (71\%) found the tools generally 'easy' to use, whilst eight (17\%) of them found them 'very difficult' to use (rating 4 out of 5) (see Fig. 12a). Similar numbers of participants (73\%) reported the actual number of inputs about to be 'about right' (see Fig. 12b). In terms of the inputs of the tools, $79 \%$ found them 'very clear and understandable' (see Fig. 12c), but a smaller number (61\%) found the output sections of the tools only 'clear and understandable' (see Fig. 12d).

Importantly, the majority (around 80\%) of the respondents wanted to use such design tools to evaluate existing or potential new shelter designs (see Fig. 12e f). This highlights 
While designing the shelters have you ever considered providing shading to reduce the amount of heat from the sun entering a shelter?

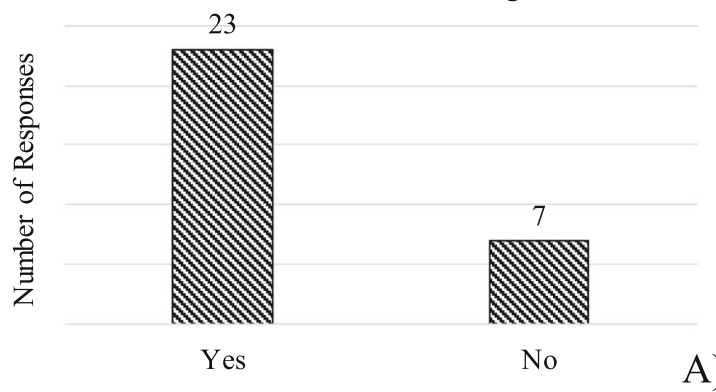

If yes, did you use calculation to help size any shading, or just follow what you believed to be a sensible/feasible policy?

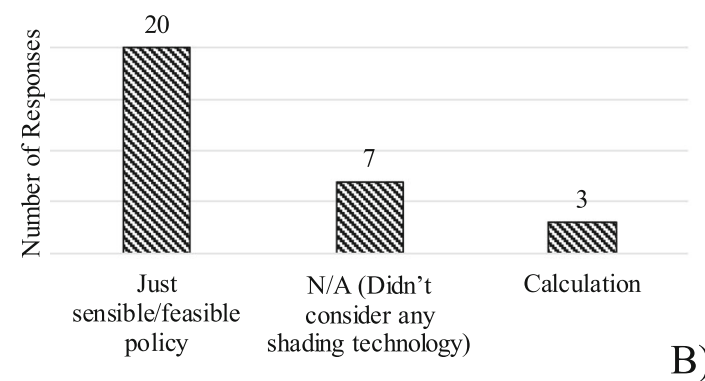

If you used some form of calculation, did you use a?

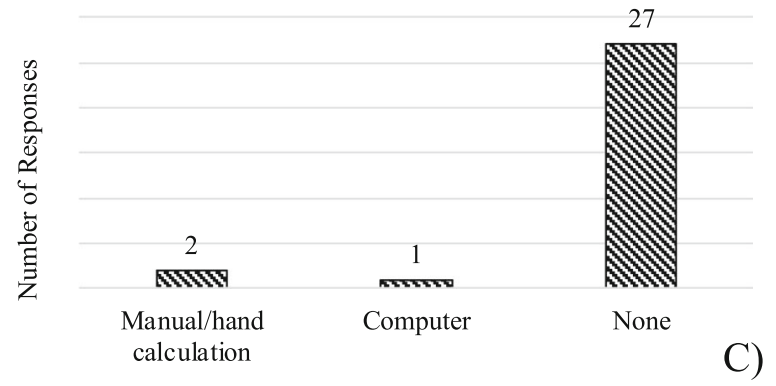

Fig. 9 Shading technologies

the clear desire and openness to adopting IT-based shelter design tools in the aid sector. Similarly, 77\% of the respondents felt positive about recommending such shelter design tools to colleagues who work in remote areas (see Fig. 12g). Finally, the participants were asked about the desired form of such a design tool and their responses are shown in Fig. 12h. The most popular format (22 participants) was a web application, but five were not interested in the form or shape of the tool. There was, however, consensus that the tool should be freely available in whatever format.

\section{Summary of the results}

It was found that the concept of daylighting was familiar to the majority of the participants, but no particular daylight calculation tool was used during the design stages of shelter projects. Very little consideration was given to the compromises caused by placing and sizing openings to let daylight in and provide ventilation. Most importantly, no use of any suitable software or design tool was evidenced and limited knowledge of technical terms was found amongst the respondents to the survey. The majority of the participants used a 'feasible/sensible' approach to choosing the size and location of openings and no accurate calculations were reported by the participants for establishing the amount of energy needed or consumed by shelters. Almost half of the participants were unfamiliar with technical terms related to the environmental impact of the buildings, which has probably contributed to shelter designs not being eco-friendly. No software was used by any of the survey participants to design shades and avoid overheating during the summer or to increase solar gain in winter. However, the majority of the participants confirmed the need for a shelter design tool that covers various aspects. As previously explained, the findings of the first survey were used to construct a shelter daylight calculation tool in the form of a Microsoft Excel spreadsheet and an environmental impact assessment tool for shelters in the form of a web application. These tools were sent to aid workers for them to use, test and review. This enabled these participants to complete the second survey. The results of this survey are shown in Fig. 12.

The majority found the tools generally 'easy' to use, whilst very few of them found the tools 'very difficult' to use and the number of inputs in the shared tools were found to be "about right" by a similar number of respondents. The inputs of the tools (shared with the participants) were found to be very clear and understandable for the majority of the survey participants.

The majority of respondents expressed the desire to use such design tools both in the evaluation of the existing or new shelter designs, which indicates the openness to adopting IT-based shelter design tools in the aid sector. It is interesting to see that after using two different forms of design tools (a spreadsheet and a web application), the majority of the participants prefer the design tool in the form of a web application. However, it is desired by the participants that the tool should be freely available has to be easy to use and freely available (minimum simulation skills required).

\section{Conclusions}

It is clear that many aspects of the modern world are connected with the growth of IT. It is also clear that the humanitarian sector has been using IT for various activities but not for shelter design. Lack of information, time, resources and the necessary skills are believed to be the key barriers (Kabra et al., 2015; Goodchild and Glennon, 2010; Bartell et al., 2006; Yeung and Harkins, 


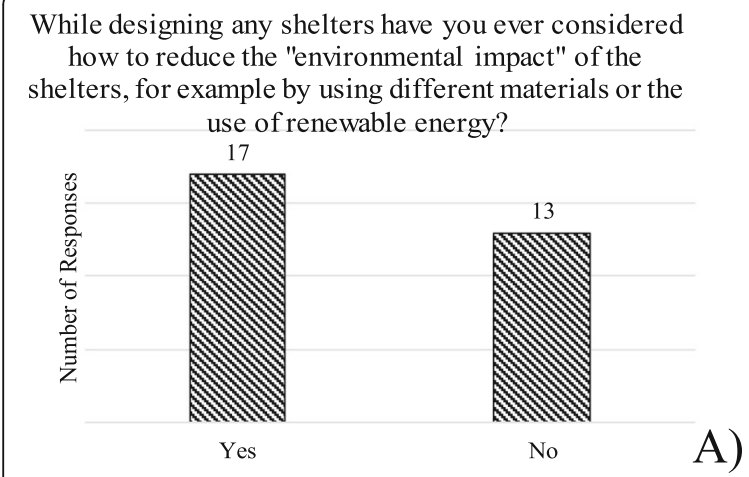

If you used some form of calculation, did you use a?

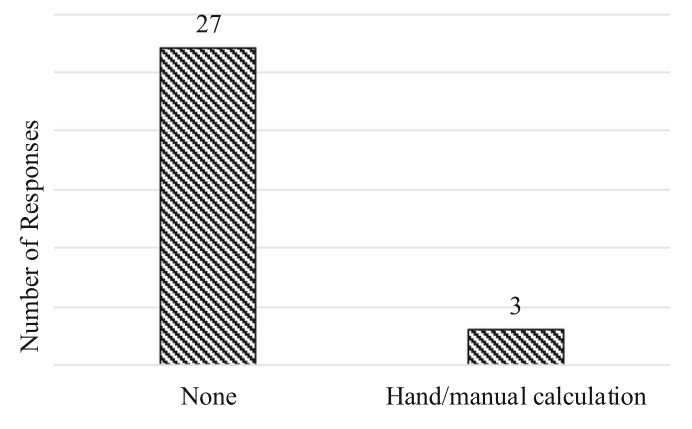

C)
Did you use calculation/calculations to help with this, or just follow what you believed to be a sensible/ policy?
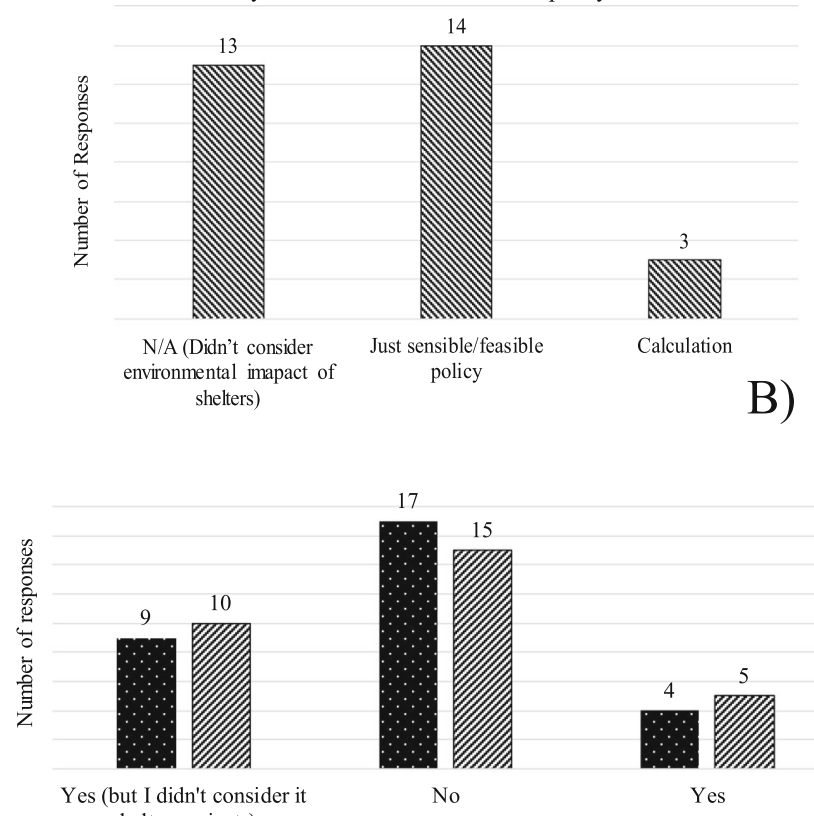
shelter projects)

- Does the term "Embodied Energy" mean anything to you?

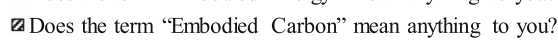

Fig. 10 Environmental impact of shelters

2011; Schware and Choudhury, 1988; Daher et al., 2015). A similar issue was highlighted by Kim et al. (2015), who noted that "we need steps to not only implement but also train professionals in the proper use of these solutions". Albadra et al. (2017) showed that many shelters do not provide suitable conditions for promoting health and wellbeing, and Fosas et al. (2018) showed that the use of engineering and computation tools can help to improve this situation.

The results of the first survey clearly show that aid workers had some understanding of building physics concepts but little knowledge of the related terminology

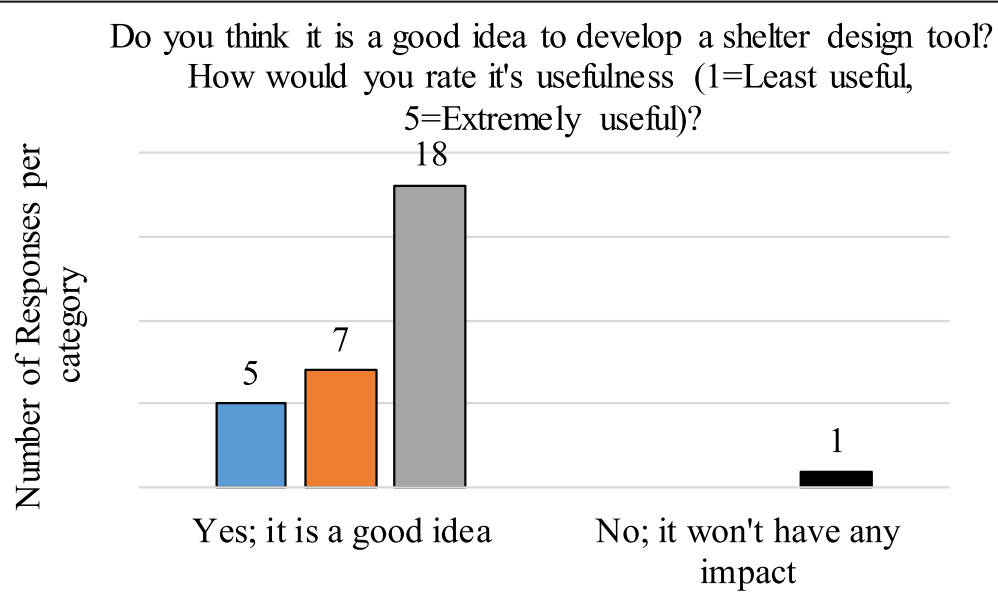

$\square$ Rated $3 \quad \square$ Rated $4 \quad \square$ Rated 5

Fig. 11 Perception of the participants 


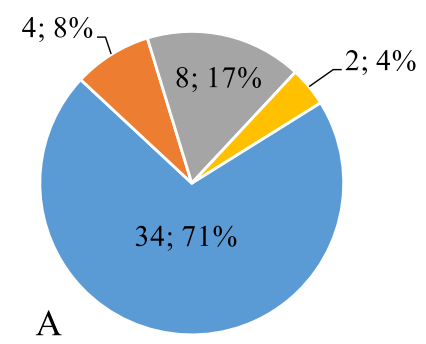

- How easy was the tool to use? (rate your answer 1 to $5 ; 1=$ very easy, $5=$ very difficult)

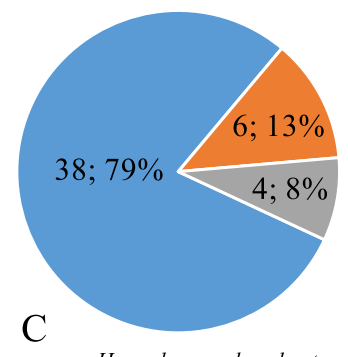

- How clear and understandable was the input section of the tool? (1 to $5 ; 1=$ very clear, $5=$ not clear at all)

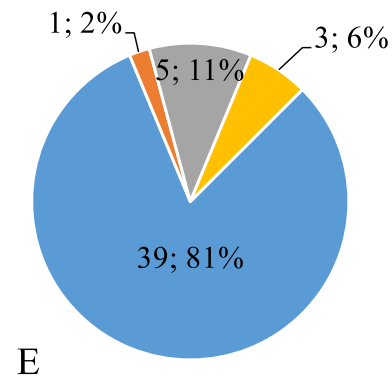

- Can you imagine using such a design tool on any topic to evaluate existing shelter designs? $(I=$ such simple tools might be very useful, $5=$ such simple tools are unlike to ever be useful)

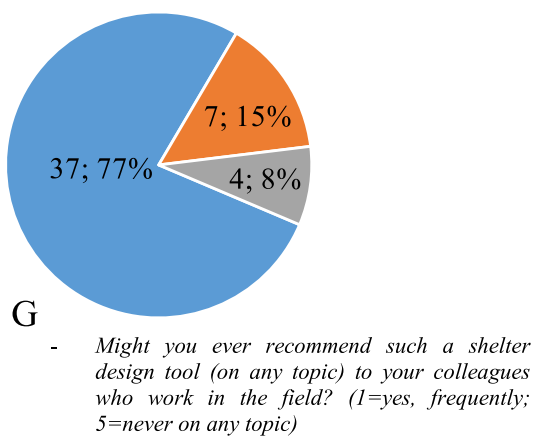

Fig. 12 Post-use evaluation survey

or units. They did not generally use calculation in design but would like to be supported by tools which are appropriate for their ability and knowledge base.

Two targeted tools (one on environmental impact and one on daylighting) were created. A second set of
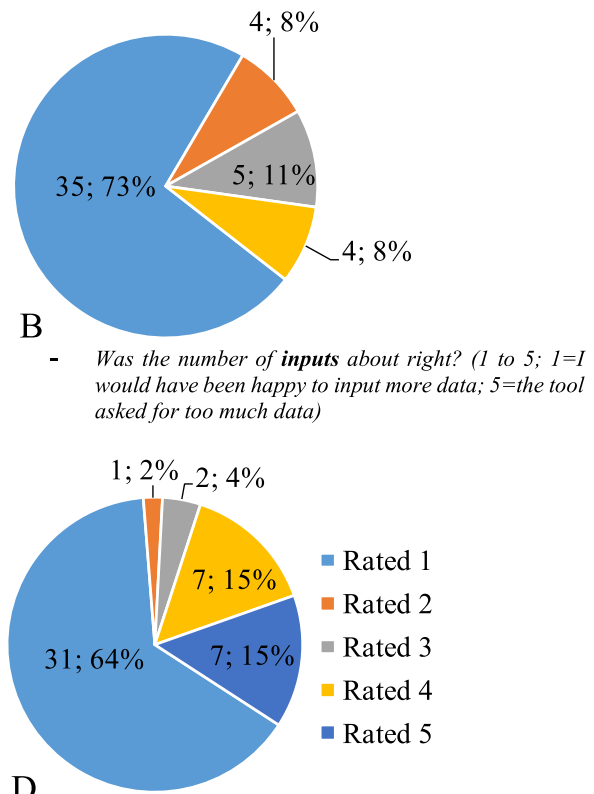

$\mathrm{D}$

How clear and understandable was the output section of the tool? ( 1 to $5 ; 1=$ very clear, $5=$ not clear at all)

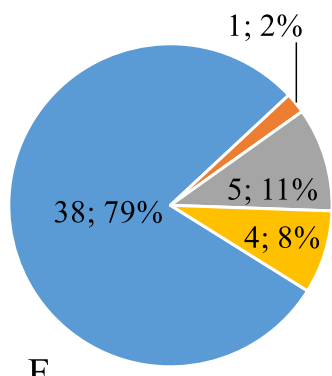

Can you imagine using such a tool on any topic to evaluate potential new shelter designs? $(1=$ such simple tools might be very useful, $5=$ such simple tools are unlike to ever be useful)

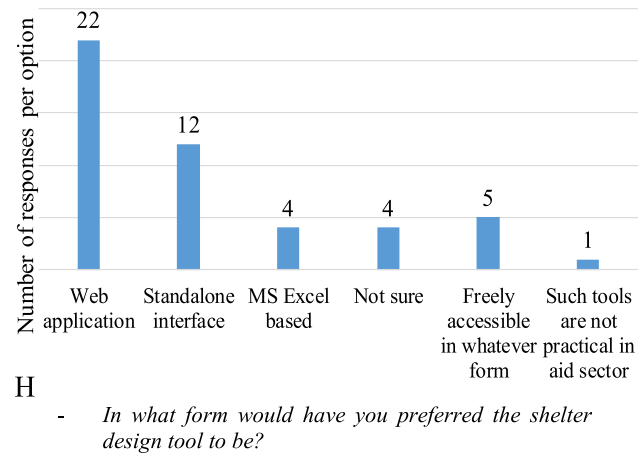

aid staff from the same agencies used these tools and assessed them. The majority found these new tools to be easy to use and $80 \%$ of them wanted to use such design tools in their work, ideally in the form of a web application. 
It is important, however, to note that whilst IT can provide many benefits for shelter projects, from design and planning to construction and implementation, it is not a complete solution in itself. Unless there is a robust framework of funding, policy and political will, amongst others, even the most advanced IT tool will fail. Nevertheless, this study has clearly identified the need and desire for computational tools to support shelter design and has shown that it is possible to create tools which are seen as useful by those working in the field.

\section{Supplementary information}

Supplementary information accompanies this paper at https://doi.org/10. 1186/s41018-020-00069-1.

Additional file 1. Appendices.

\section{Acknowledgements}

We thank all those aid workers who participated in the surveys. We also thank Aude Matard who helped us in developing the shelter environmental impact assessment tool (web application).

\section{Authors' contributions}

Each author has made a substantial contribution in preparing this journal article and they have approved the final version. The authors were involved in different aspects of the paper as follows: N. K and D.C developed the conception or design of the work; data collection tools were constructed by N.K and D.C; data analysis and interpretation was done by N.K, D.C and P.S; the article was drafted and compiled by N.K; critical revision of the article was carried out by P. S; J. J.H; A.C. The final approval of the version to be published D.C and N.K.

\section{Authors' information}

Noorullah Kuchai: PhD candidate, Department of Architecture \& Civil Engineering, University of Bath, Bath, UK. Email address: nk615@bath.ac.uk Noorullah is a civil engineer with MSc in construction management. He has worked for several years with various aid agencies in some of the most challenging environments delivering humanitarian assistance such as shelters, community access roads, and other reintegration projects for displaced people. His current research is about constructing a building physics tool and testing it in refugee camps, which will be used to design better shelters for the displaced.

Read more@ https://www.hhftd.net/research-team \& https://researchportal. bath.ac.uk/en/persons/noorullah-kuchai

David Coley: Professor, Department of Architecture \& Civil Engineering, University of Bath, Bath, UK. Email address: dac33@bath.ac.uk David Coley is Professor of Low Carbon Design and head of the Energy and the Design of Environments research centre. His research focuses on minimising the energy use of buildings through a process of physical design and an understanding of occupant behaviour. He is also interested in citywide energy modelling. David Coley received a BSC in Physics in 1985 and a PhD in theoretical nuclear physics in 1989 (both from Surrey University). During this time he also worked briefly for the UK Atomic Energy Authority. He joined the Centre for Energy and the Environment at Exeter University in 1998, where he worked until joining Bath as Professor of Low Carbon Design in 2011. Whilst at Exeter, his main interests were in low energy design (including Passivhaus), renewables, estimating the impact of climate change on the built environment and evolutionary computation. He was also a founding member of a London based hedge fund. David's main research interests are finding out why buildings use energy, how little they could use and where this energy might come from.

Read more@ https://researchportal.bath.ac.uk/en/persons/david-coley Dr. Paul Shepherd: Senior Lecturer, Department of Architecture \& Civi Engineering, University of Bath, Bath, UK. Email address: ps281@bath.ac.uk Paul's research involves the development of new computer-based tools for both architects and engineers to help with the creation, optimisation and realisation of complex geometry buildings. Until very recently, computers had been used almost exclusively by the building industry as a form of electronic paper, helping designers to communicate their ideas, but not actually contributing to the design process itself. However, with the recent development in computational speed, graphics and networking, this means that the full potential of the computer is being wasted. By combining mathematical techniques such as Dynamic Relaxation, Multi-Objective Optimisation, and Parametric Modelling, Paul aims to facilitate the design of complex geometry forms, using computational techniques to improve the potential structural and environmental performance and constructability of the resulting shapes. Read more @ https://researchportal.bath.ac.uk/en/persons/paul-shepherd Dr. Juliana Holley: Senior Lecturer, Department of Architecture \& Civil Engineering, University of Bath, Bath, UK. Email address: jch51@bath.ac.uk Dr Juliana Calabria Holley is a Lecturer in the Department of Architecture and Civil Engineering. Her research area is in construction materials, specialising in micro and nanostructure of adobe and fired bricks, cementitious materials, surface engineering via sol-gel technology, adsorption process and porosity systems. She obtained her Architect diploma from Catholic University of Minas Gerais (1999), Brazil. She acted as a selfemployed Architect from1999 until 2009 specialising in the residential sector. During this time she also obtained her master's from Federal University of Minas Gerais, (2004) Brazil and her PhD from Federal University of Minas Gerais, Brazil and Imperial College of London, United Kingdom (2008), both in the field of Materials Science and Engineering. Her PhD research focused on developing breathable protective coatings for the sustainable and lowembodied energy material, adobe brick.

Read more@ https://researchportal.bath.ac.uk/en/persons/juliana-holley Dr. Alexander Copping: Senior Lecturer, Department of Architecture \& Civil Engineering, University of Bath, Bath, UK. Email address: absagac@bath.ac.uk My research interests revolve around the relationship between project complexity, project management methodologies and the management of resources pertaining to "integrated delivery" in project environments. Within this theme I am currently supervising PhD projects addressing issues of process innovation, including BIM maturity assessment tools, knowledge sharing, value benchmarking, sustainable construction management practices and end-of-life component management. I also have a research interest in teaching and learning innovations which has naturally evolved from managing distance and flexible learning programmes and the need to develop innovative methods of delivery.

Read more@ https://researchportal.bath.ac.uk/en/persons/alexander-copping Aude Matard: MSc Student, Department of Architecture \& Civil Engineering, University of Bath, Bath, UK. Email address: am2444@bath.ac.uk

\section{Funding}

This research was funded by EPSRC's Healthy Housing for the Displaced (EP/P029175/1) and dCarb (EP/L016869/1) projects.

\section{Availability of data and materials}

The data can be found at https://doi.org/10.15125/BATH-00550. The environmental assessment tool can be found at https://www.hhftd.net/ calculator.

\section{Competing interests}

There are no conflicts of interest to declare and the stated authors who are all aware of its content and approve its submission have written the article.

Received: 17 July 2019 Accepted: 12 March 2020

Published online: 03 April 2020

\section{References}

Ajam, R., 1998. Thermal comfort in low-cost refugee shelters; a computer simulation study in Waqas, a lower desert valley area in Jordan. UNRWA-HQ Amman.

Albadra D, Vellei M, Coley D, Hart J (2017) Thermal comfort in desert refugee camps: an interdisciplinary approach. Building and Environment 124:460-477 https://doi.org/10.1016/j.buildenv.2017.08.016

Alexander DE (2014a) Communicating earthquake risk to the public: the trial of the "L'Aquila Seven". Natural Hazards 72(2):1159-1173. https://doi.org/10. 1007/s11069-014-1062-2 
Alexander DE (2014b) Social media in disaster risk reduction and crisis management. Sci Eng Ethics, 20(3), pp. 717-33. DOl: https://doi.org. https:// doi.org/10.1007/s11948-013-9502-z

Al-Ghamdi, M.S., 1993. Assessment and improvement on thermal conditions inside pilgrimage tents at Makkah, Saudi Arabia. http://theses.ncl.ac.uk/jspui/ handle/10443/403

Al-Hemiddi NA, Al-Saud KAM (2001) The effect of a ventilated interior courtyard on the thermal performance of a house in a hot-arid region. Renewable Energy 24(3-4):581-595 https://doi.org/10.1016/S0960-1481(01)00045-3

Andresen J, Baldwin A, Betts M, Carter C, Hamilton A, Stokes E, Thorpe T (2002) A framework for measuring IT innovation benefits. Journal of Information Technology in Construction (ITcon) 5(4):57-72 http://itcon.org/2000/4/

Anema A, Kluberg S, Wilson K, Hogg RS, Khan K, Hay SI, Tatem AJ, Brownstein JS (2014) Digital surveillance for enhanced detection and response to outbreaks. Lancet Infect Dis 14(11):1035-1037. https://doi.org/10.1016/S14733099(14)70953-3

Antonelli D, Litwin P, Stadnicka D (2018) Multiple System Dynamics and Discrete Event Simulation for manufacturing system performance evaluation. Procedia CIRP 78:178-183 https://doi.org/10.1016/j.procir.2018.08.312

Arnold RD, Yamaguchi H, Tanaka T (2018) Search and rescue with autonomous flying robots through behavior-based cooperative intelligence. Journal of International Humanitarian Action, 3(1), p. 18. https://doi.org/10.1186/s41018018-0045-4

Ashbridge, J., Heykoop, L., Bengono-Muanze, A., Lisa Irvine, B.C., Lisa, F., Cook, S., Mazzone, C., Curtis, D., Milne, J., Cusack, A., Müller, C. \& Evangeliou, M., 2012 Transitional shelter guidelines In: N.N. Brian Kelly, Bill Flinn, ed. Wold-wide: Shelter Centre, International Organization for Migration (IOM), Department for International Development (DFID), Swedish International Development Coorporation Agency (SIDA), p. 219. https://www.iom.int/files/live/sites/iom/ files/What-We-Do/docs/Transitional-Shelter-Guidelines.pdf

Ashmore J, Babister E, Corsellis T, Fowler J, Kelman I, McRobie A, Manfield P, Spence R, Vitale A, Battilana R, Crawford K (2003) Diversity and adaptation of shelters in transitional settlements for IDPs in Afghanistan. Disasters 27(4): 273-287. https://doi.org/10.1111/j.0361-3666.2003.00233.x

Atmaca A, Atmaca N (2016) Comparative life cycle energy and cost analysis of post-disaster temporary housings. Applied energy 171:429-443 https://doi. org/10.1016/j.apenergy.2016.03.058

Attia, S., 2014. Assessing the thermal performance of Bedouin tents in hot climates, ASHRAE Energy \& Indoor Environment for Hot Climates. https://pdfs. semanticscholar.org/8082/7bfe590a2e850d209248b2d8528c1bd839c1.pdf

Barr P (2011) Staying connected. Social media put to work when disaster strikes. Modern healthcare 41(36):33-33

Bartell AL, Lappenbusch S, Kemp RB, Haselkorn M (2006) Improving humanitarian relief information and communication systems through research. In 2006 IEEE International Professional Communication Conference (pp. 156-162). IEEE. https://doi.org/10.1504/IJBCRM.2012.051866

Belliveau J (2016) Humanitarian access and technology: opportunities and applications. Procedia engineering 159:300-306 https://doi.org/10.1016/j. proeng.2016.08.182

Benrós D, Granadero V, Duarte JP, Knight T (2011) Automated design and delivery of relief housing: the case of post-earthquake Haiti. Designing Together, CAAD Futures, pp 247-263

Bhattacharya A (2001) Role of information technology in construction industry. Indian Highways 29(2) http://worldcat.org/oclc/1790571

Biswajit, M. \& Bhattacherjee, B., 2015. Use of Information Technology in Emergency and Disaster Management. DOI: 10.11648/j.ajep.20150402.15

Bond C (2011) Adaptive reuse: Explaining collaborations within a complex process (Doctoral dissertation). Public Policy \& Management, University of Oregon, Department of Planning

Bortnick J (2010) Information technology and the developing world: Opportunities and obstacles. The Information Society 2(2):157-170. https:// doi.org/10.1080/01972243.1983.9959974

Braun V, Clarke V (2014) What can "thematic analysis" offer health and wellbeing researchers? International journal of qualitative studies on health and wellbeing, 9. DOI. https://doi.org/10.3402/qhw.v9.26152

Carrasco S, O'Brien D (2018) The Role of Humanitarian Agencies in Reconstruction and Development of Disaster Affected Communities in Japan and the Philippines. Procedia Engineering 212:606-613. https://doi.org/10. 1016/j.proeng.2018.01.078

Chang Y, Wilkinson S, Brunsdon D, Seville E, Potangaroa R (2011) An integrated approach: managing resources for post-disaster reconstruction. Disasters 35(4):739-765
Chang Y, Wilkinson S, Potangaroa R, Seville E (2010) Resourcing challenges for post-disaster housing reconstruction: a comparative analysis. Build Res Inf 38(3):247-264

Chaudhri S, Cordes K, Miller N (2019) Humanitarian health programming and monitoring in inaccessible conflict settings: a literature review. Journal of International Humanitarian Action, 4(1), p. 9. https:/doi.org/10.1186/s41018-019-0055-x

Cheng Y (2018) How Social Media Is Changing Crisis Communication Strategies: Evidence from the Updated Literature. Journal of contingencies and crisis management 26(1):58-68. https://doi.org/10.1111/1468-5973.12130

Chu, T.J., Chang, A.P., Hwang, C.L. \& Lin, J.D., Intelligent and green buildings project management scope definition using project definition rating index (PDRI). In: Advanced Materials Research, 2014. Trans Tech Publ, pp. 3008-3011.

Clarke V, Braun V (2013) Teaching thematic analysis: Overcoming challenges and developing strategies for effective learning. The psychologist 26(2):120-123

Comes T (2016) Technology innovation and Big Data for humanitarian operations. J Humanit Logist Sup 6(3):262-263

Cornaro C, Sapori D, Bucci F, Pierro M, Giammanco C (2015) Therma performance analysis of an emergency shelter using dynamic building simulation. Energy and Buildings 88:122-134

Crawford C, Manfield P, McRobie A (2005) Assessing the thermal performance of an emergency shelter system. Energy and buildings 37(5):471-483

Dabaieh M, Alwall J (2018) Building now and building back. Refugees at the centre of an occupant driven design and construction process. Sustainable cities and society 37:619-627

Daher E, Kubicki S, Halin G (2015) A parametric process for shelters and refugees' camps design

Daubman, B.R., Cranmer, H., Black, L. \& Goodman, A., 2019. How to talk with dying patients and their families after disasters and humanitarian crises: a review of available tools and guides for disaster responders. Journal of International Humanitarian Action, 4(1), p. 10.

Davis, D., Burry, J. \& Burry, M., Untangling parametric schemata: enhancing collaboration through modular programming. In: Proceedings of the 14th international conference on Computer Aided Architectural Design, University of Liege, Liege, 2011.

De Dear R, Brager GS (1998) Developing an adaptive model of thermal comfort and preference

De Longueville B, Annoni A, Schade S, Ostlaender N, Whitmore C (2010) Digital earth's nervous system for crisis events: real-time sensor web enablement of volunteered geographic information. International Journal of Digital Earth 3(3):242-259

Dong, L., Wang, Y., Li, H.X., Jiang, B. \& Al-Hussein, M., 2018. Carbon Reduction Measures-Based LCA of Prefabricated Temporary Housing with Renewable Energy Systems. Sustainability, 10(3), p. 718

Downs E (1987) A contextual view of development information technology. The Information Society 5(2):119-132

Dowson, N. (2018). Humanitarian drones and other anachronisms. [online] New Internationalist. Available at: https://newint.org/features/2018/04/01/cyberhumanitarians-drones-aid [Accessed: 4 December 2018]

El-Anwar O, El-Rayes K, Elnashai A (2009) Maximizing temporary housing safety after natural disasters. Journal of Infrastructure Systems 16(2):138-148

Elliman T, Orange G (2000) Electronic commerce to support construction design and supply-chain management: a research note. International Journal of Physical Distribution \& Logistics Management 30(3/4):345-360

Erskine, M.A. and Gregg, D.G., 2012. Utilizing Volunteered Geographic Information to Develop a Real-Time Disaster Mapping Tool: A Prototype and Research Framework. In CONF-IRM (p. 27).

Escamilla EZ, Habert G (2015a) Global or local construction materials for postdisaster reconstruction? Sustainability assessment of twenty post-disaster shelter designs. Building and Environment 92:692-702

Escamilla, E.Z. \& Habert, G., 2015b. Regionalizing the environmental impact of bamboo-based buildings by integrating life cycle assessment with geographic information systems. A comparative case study in Colombia. In: 10th World Bamboo Congress, Korea,.

European Parliamentary Research Service., 2017. Technologies For Humanitarian Aid [Online]. Brussels: European Parliamentary Research Service. Available from: https://epthinktank.eu/2017/09/25/technologies-for-humanitarian-aid/ [Accessed: 13 June 2019 2019].

European Parliamentary Research Service., 2019. Using Technology To Help Those In Need [Online]. Global: European Parliamentary Research Service. Available from: https://epthinktank.eu/2019/05/13/using-technology-to-help-those-inneed/ [Accessed: 13 June 2019 2019]. 
Farley J, Hecht L (1999) Open computing technologies as infrastructures for disaster management. GDIN conference, Mexico City, May, In

Félix D, Branco JM, Feio A (2013) Temporary housing after disasters: A state of the art survey. Habitat International 40:136-141

Felter, E. (2018). Digital Skills for Humanitarian Aid: How Tech Can Help | Okta. [online] Okta. Available at: https:/www.okta.com/blog/2018/11/digital-skillsfor-humanitarian-aid-how-tech-can-help/ [Accessed: 4 December 2018].

Fosas D, Albadra D, Natarajan S, Coley DA (2018) Refugee housing through cyclic design. Architectural Science Review 61(5):327-337

Gilman, D., 2014. Humanitarianism in the age of cyber-warfare: towards the principled and secure use of information in humanitarian emergencies. United Nations Office for the Coordination of Humanitarian Affairs.

Global Shelter Cluster (2018). The State of Humanitarian Shelter and Settlements 2018. Beyond the Better Shed: Prioritizing People. [online] Geneva: International Federation of Red Cross and Red Crescent Societies and the United Nations High Commissioner for Refugee. Available at: https://www. sheltercluster.org/resources/library/state-humanitarian-shelter-andsettlements [Accessed 23 Dec. 2019].

Goodchild MF, Glennon JA (2010) Crowdsourcing geographic information for disaster response: a research frontier. International Journal of Digital Earth 3(3):231-241

Grimes S, Lyons G (1994) Information technology and rural development: unique opportunity or potential threat? Entrepreneurship \& Regional Development 6(3):219-237

Guest G, MacQueen KM, Namey EE (2011) Applied thematic analysis. Sage Publications

Guest G, MacQueen KM, Namey EE (2012) Introduction to applied thematic analysis. Applied thematic analysis 3:20

Hammon L, Hippner H (2012) Crowdsourcing. WIRTSCHAFTSINFORMATIK 54(3):165-168

Harvard Humanitarian Initiative., 2011. Disaster Relief 2.0: The Future of Information Sharing in Humanitarian Emergencies. Washington, D.C. and Berkshire, UK: U.F.V.F.T. Partnership.

Hosein G, Nyst C (2013) Aiding surveillance: an exploration of how development and humanitarian aid initiatives are enabling surveillance in developing countries. Available at SSRN 2326229

Humphreys \& A M., 1976., Field studies of thermal comfort compared and applied. The Building Services Engineer, 44, p. 27.

Ismail D, Majid TA, Roosli R, Ab Samah N (2014) Project Management Success for Post-Disaster Reconstruction Projects: International NGOs Perspectives. Proc Econ Financ 18:120-127

Jacobsen KL (2017) On Humanitarian Refugee Biometrics and New Forms of Intervention. Journal of Intervention and Statebuilding 11(4):529-551

Jinuntuya P, Theppipit J (2007) Temporary housing design and planning software for disaster relief decision support system. In: Caadria 2007: Proceedings of the 12th International Conference on Computer-Aided Architectural Design Research in Asia, pp 639-644

Kabra G, Ramesh A, Arshinder K (2015) Identification and prioritization of coordination barriers in humanitarian supply chain management. International Journal of Disaster Risk Reduction 13:128-138

Kalkman, J.P., 2018., Practices and consequences of using humanitarian technologies in volatile aid settings. Journal of International Humanitarian Action, 3(1), p. 1

Kim JG, Lee J, Ahn BL, Shin H, Yoo S, Jang CY, Song D, Kim J (2015) Indoor Thermal Environment of Temporary Mobile Energy Shelter Houses (MeSHs) in South Korea. Energies 8(10):11139-11152

Kleinau EF (2015) Social Media and Aid Effectiveness. In: Beracochea E (ed) Improving Aid Effectiveness in Global Health, 1st edn. New York, NY, Springer New York, pp 241-253

Kneifel J, O'Rear E (2017) Reducing the impacts of weather variability on long-term building energy performance by adopting energy-efficient measures and systems: a case study. Journal of Building Performance Simulation 10(1):58-71

Knight I (1988) What intensity of fire can a fire fighter survive in a reflective shelter. Fire technology 24(4):312-332

Kong, C.W., Li, H. and Love, P.E.D., 2001. An e-commerce system for construction material procurement. Construction Innovation, 1(1), pp.43-54 DOl: https:// doi.org/10.1108/14714170110814505

Kotireddy R, Hoes P-J, Hensen JLM (2018) Integrating robustness indicators into multi-objective optimization to find robust optimal low-energy building designs. Journal of Building Performance Simulation, pp:1-20

Langston YL, Langston CA (2008) Reliability of building embodied energy modelling: an analysis of 30 Melbourne case studies. Construction Management and Economics 26(2):147-160
Lessing, J., Stehn, L. and Ekholm, A., 2005. Industrialised housing: definition and categorization of the concept. In Annual conference of the International Group for Lean Construction: 18/07/2005-21/07/2005 (pp. 471-480). International group for lean construction.

Love PED, Irani Z, Edwards DJ (2005) Researching the investment of information technology in construction: An examination of evaluation practices. Automation in Construction 14(4):569-582

Lüge T (2014) GIS support for the MSF Ebola response in Guinea in:2014

Manfield P (2000) Modelling of a cold climate emergency shelter prototype and a comparison with the United Nations winter tent. Unpublished thesis, University of Cambridge at http://www.shelterproject.org

Molnár M, Andersson R, Ekholm A (2019) Benefits of ICT in the construction industry - characterization of the present situation in house-building processes

Nguyen A-T, Reiter S, Rigo P (2014) A review on simulation-based optimization methods applied to building performance analysis. Applied Energy 113: 1043-1058

O'Driscoll D (2017) UAVs in humanitarian relief and wider development contexts

Obyn S, Van Moeseke G, Virgo V (2014) The thermal performance of shelter modelling: improvement of temporary structures. Mobile and Rapidly Assembled Structures IV 136:83

Oldham K, Astbury K (2018) Evolution of disaster risk governance in Greater Manchester: a case study from the UK. Procedia Engineering 212:7-14

Ouyang M (2014) Review on modeling and simulation of interdependent critical infrastructure systems. Reliability Engineering \& System Safety 121:43-60

Ozumba AOU, Shakantu W (2018) Exploring challenges to ICT utilisation in construction site management. Construction Innovation 18(3):321-349

Raghad, A.S. \& Dave, E., The mesh network for refugees and displaced persons. In: 2016 IEEE Global Humanitarian Technology Conference (GHTC), 13-16 Oct. 2016 2016. pp. 47-53.

Ramalingam, B., Scriven, K. \& Foley, C., 2009., Innovations in international humanitarian action. Overseas Development Institute.

Ben Ramalingam, 2016. 10 Frontier Technologies for International Development [Online]. Oxfam. Available from: https://oxfamblogs.org/fp2p/10-frontiertechnologies-for-international-development/ [Accessed: 13 July 2019].

Rigaud KK, Bergmann J, Clement V, Ober K, Schewe J, Adamo S, McCusker B, Heuser S, Midgley A (2018) Groundswell: Preparing for Internal Climate Migration. W. Bank, Washington, DC

Sabie, S., Chen, J., Abouzied, A., Hashim, F., Kahlon, H. \& Easterbrook, S., Shelter dynamics in refugee and IDP camps: Customization, permanency, and opportunities. In: Proceedings of the 2017 Workshop on Computing Within Limits, 2017. ACM, pp. 11-20.

Saleh SY (2011) Evaluation and enhancement of environmental performance of refugee shelters in Palestine. University of Nottingham

Samuelhall.org. 2012. [online] Available at: http://samuelhall.org/wp-content/ uploads/2013/11/UNHCR-Shelter-Assistance-Programme-Evaluation.pdf [Accessed: 3 Sep. 2018].

Sandvik KB, Gabrielsen Jumbert M, Karlsrud J, Kaufmann M (2014) Humanitarian technology: a critical research agenda. International Review of the Red Cross 96(893):219-242

Schware R, Choudhury Z (1988) Aid agencies and information technology development. Information Technology for Development 3(2):145-158

Soesilo, D. (2019). How Drones Can Help in Humanitarian Crises - European Civil Protection and Humanitarian Aid Operations - European Commission. [online] European Civil Protection and Humanitarian Aid Operations - European Commission. Available at: https:/ec.europa.eu/echo/field-blogs/stories/howdrones-can-help-humanitarian-crises_en [Accessed 26 Dec. 2019].

Soesilo D et al (2016) Drones in Humanitarian Action: A guide to the use of airborne systems in humanitarian crises. FSD Report:1-60 http://drones.fsd. ch/wpcontent/uploads/2016/11/Drones-in-Humanitarian-Action.pdf

Song Y, Mithraratne N, Zhang H (2016) Life-time performance of post-disaster temporary housing: A case study in Nanjing. Energy and Buildings 128:394-404

Susanti L (2015) Thermal comfort evaluation of emergency tent using PMV and PPD model. In, Proceedings of the International MultiConference of Engineers and Computer Scientists

Jason Susim, 2019., 7 tech trends that are transforming humanitarian aid [Online]. Global: Mercy Corps. Available from: https://www.mercycorps.org/articles/7tech-trends-transforming-humanitarian-aid [Accessed 13 June 2019].

Tasevski, S. (2018). Drones for Humanitarian Aid. [online] Dronebelow.com. Available at: https://dronebelow.com/2018/11/27/drones-for-humanitarianaid/ [Accessed 20 Dec. 2019]. 
Taylor NAS, Haberley BJ, Hoyle DJR (2015) Thermal performance trials on the habitability of private bushfire shelters: part 1. International Journal of Biometeorology 59(8):983-993

Tuckett AG (2005) Applying thematic analysis theory to practice: a researcher's experience. Contemporary nurse 19(1-2):75-87

UNHCR, 2018., Global trends: Forced displacement in 2016 [Online]. Geneva: United Nations High Commissioner for Refugees. Available from: http://www. internal-displacement.org/global-report/grid2018/ [Accessed 13 February 2019].

UNOCHA, 2018., datatrends 2017: Global Force displacements [Online]. United Nations Office for the Coordination of Humanitarian Affairs. Available from: http://interactive.unocha.org/publication/datatrends2017/ [Accessed 2018].

Wang, Q. \& E.Taylor, J., 2014. Quantifying, Comparing Human Mobility Perturbation during Hurricane Sandy, Typhoon Wipha, Typhoon Haiyan. Procedia Economics and Finance, 18, pp. 33-38.

Wilson, C. \& Jumbert, M.G., 2018., The new informatics of pandemic response: humanitarian technology, efficiency, and the subtle retreat of national agency. Journal of International Humanitarian Action, 3(1), p. 8.

Wutthikornthanawat, W.O.R.A.W.U.T., Jinuntuya, P.I.N.Y.O. and Rongviriyapanich, D. S., 2007. Multiuser tangible interface for public participation development of low-cost housing project design and planning'. In Proeeedings of the 12th International Conference on Computer-Aided Architectural Design Research in Asia-Digitization and Globalizatin (pp. 37-43)

Yates D, Paquette S (2011) Emergency knowledge management and social media technologies: A case study of the 2010 Haitian earthquake. International Journal of Information Management 31(1):6-13

Yeung WK, Harkins I (2011) Digital architecture for humanitarian design in post-disaster reconstruction. International Journal of Architectural Computing 9(1):17-31

Zhu F, Yao Y, Tang W, Tang J (2017) A hierarchical composite framework of parallel discrete event simulation for modelling complex adaptive systems. Simulation Modelling Practice and Theory 77:141-156

\section{Publisher's Note}

Springer Nature remains neutral with regard to jurisdictional claims in published maps and institutional affiliations.

\section{Submit your manuscript to a SpringerOpen ${ }^{\circ}$ journal and benefit from:}

- Convenient online submission

- Rigorous peer review

- Open access: articles freely available online

- High visibility within the field

- Retaining the copyright to your article

Submit your next manuscript at $\boldsymbol{\nabla}$ springeropen.com 